\title{
Quimioprevenção e câncer no contexto brasileiro: Da higidez ao diagnóstico
}

\author{
Chemoprevention and cancer in the brazilian context: From healthiness to diagnosis \\ Quimioprevención y câncer en el contexto brasileño: De la salubridad al diagnóstico
}

Recebido: 22/06/2021 | Revisado: 30/06/2021 | Aceito: 05/07/2021 | Publicado: 15/07/2021

\author{
Mariane Minussi Baptistella \\ ORCID: https://orcid.org/0000-0002-9535-5204 \\ Universidade Federal de Alfenas, Brasil \\ E-mail: mariane.baptistella@hotmail.com \\ Carolina Sales de Oliveira \\ ORCID: https://orcid.org/0000-0001-8812-2210 \\ Universidade Federal de Alfenas, Brasil \\ E-mail: csales.biomed@gmail.com \\ Raphaela Rebeca Silveira Assunção \\ ORCID: https://orcid.org/0000-0003-4326-5220 \\ Universidade Federal de Alfenas, Brasil \\ E-mail: raphaelarebeca@outlook.com \\ Pollyanna Francielli de Oliveira \\ ORCID: https://orcid.org/0000-0002-1646-0277 \\ Universidade Federal de Alfenas, Brasil \\ E-mail: pollyfoliveira@gmail.com
}

\begin{abstract}
Resumo
O câncer representa um dos maiores problemas de saúde pública do mundo. Apesar dos avanços crescentes e de alguns sucessos ocasionais, pacientes e profissionais da saúde permanecem enfrentando diversos contratempos procedentes da terapia oncológica. Nesse sentido, a quimioprevenção é interessante, pois implica evitar o sofrimento causado pelo câncer, tendo potencial efeito antes do diagnóstico, no prognóstico e, também, no tratamento. Nesta revisão, teve-se como objetivo elencar as principais abordagens quimiopreventivas, a nível primário, secundário e terciário, para os tumores mais frequentes no Brasil e que possuem correlação com hábitos cotidianos adotados. Para isso, foi realizado um levantamento bibliográfico das publicações disponíveis nas bases da National Library of Medicine (NIH - PubMed) e Scholar Google dos últimos 20 anos. Utilizou-se os descritores: "chemoprevention", "cancer chemoprevention" "non melanoma skin cancer", "lung cancer", "breast cancer", e "colorectal cancer". São notáveis os resultados obtidos por diversos estudos in vitro e in vivo, tal qual as histórias de sucesso clínico. Não obstante, os desafios ainda são muitos devido, sobretudo, às variáveis encontradas nas respostas individuais dos pacientes, as quais podem ser influenciadas por especificidades do quadro clínico, e entre outros fatores, como também as limitações de investimento e adesão. Futuras pesquisas e investimento em educação e conscientização do público em geral e de profissionais da saúde, a respeito dos benefícios por trás da quimioprevenção do câncer, possibilitariam a ampla aplicação da quimioprevenção e beneficiariam diversos âmbitos da saúde.
\end{abstract}

Palavras-chave: Quimioprevenção do câncer; Câncer de pele não-melanoma; Câncer de pulmão; Câncer de mama; Câncer colorretal.

\begin{abstract}
Cancer represents one of the biggest public health problems in the world. Despite increasing advances and occasional successes, patients and healthcare professionals continue to face numerous setbacks from cancer therapy. In this direction, the concept of chemoprevention is intuitively instigating, as it implies avoiding suffering from cancer, having a potential effect before diagnosis, on prognosis and also on treatment. The goal of this review is to list the main possible chemopreventive approaches, at primary, secondary and tertiary levels, for the most frequent tumors in Brazil, which have a strong correlation with everyday habits adopted. To achieve that, a bibliographic survey of the publications available in the databases of the National Library of Medicine (NIH - PubMed) and Scholar Google for the last 20 years was carried out. The descriptors used were: "chemoprevention", "cancer chemoprevention", "non melanoma skin cancer", "lung cancer", "breast cancer", and "colorectal cancer". The results obtained by several in vitro and in vivo studies are remarkable, as well as the clinical success stories. Nevertheless, the challenges are still many, due, mainly, to the variables found in the individual responses of the patients, which can be influenced by specificities of the clinical condition, as well as investment limitations and adherence. Future research and investment in education and awareness of both the general public and health professionals, regarding the benefits behind cancer chemoprevention, would enable the wide application of chemoprevention and benefit several areas of healthcare.
\end{abstract}

Keywords: Cancer chemoprevention; Non-melanoma skin cancer; Lung cancer; Breast cancer; Colorectal cancer. 


\begin{abstract}
Resumen
El cáncer representa uno de los mayores problemas de salud pública del mundo. A pesar de los crecientes avances y éxitos ocasionales, los pacientes y los profesionales de la salud continúan enfrentándose a varios reveses de la terapia del cáncer. En este sentido, la quimioprevención es interesante, ya que implica evitar el sufrimiento que provoca el cáncer, teniendo un efecto potencial antes del diagnóstico, sobre el pronóstico y, también, sobre el tratamiento. En esta revisión, el objetivo fue enumerar los principales abordajes quimiopreventivos, a nivel primario, secundario y terciario, para los tumores más frecuentes en Brasil, que se correlacionan con los hábitos diarios adoptados. Para ello, se realizó un relevamiento bibliográfico de las publicaciones disponibles en las bases de datos de la Biblioteca Nacional de Medicina (NIH - PubMed) y Scholar Google en los últimos 20 años. Se utilizaron los siguientes descriptores: "quimioprevención", "quimioprevención del cáncer", "cáncer de piel no melanoma", "cáncer de pulmón", "cáncer de mama" y "cáncer colorrectal". Los resultados obtenidos por varios estudios in vitro e in vivo son notables, al igual que los casos de éxito clínico. Sin embargo, los desafíos aún son muchos, principalmente por las variables encontradas en las respuestas individuales de los pacientes, las cuales pueden estar influenciadas por especificidades del cuadro clínico, y entre otros factores, así como por limitaciones de inversión y adherencia. La investigación y la inversión futuras en educación y concienciación del público en general y los profesionales de la salud, con respecto a los beneficios de la quimioprevención del cáncer, permitirían la amplia aplicación de la quimioprevención y beneficiarían a varias áreas de la salud.
\end{abstract}

Palabras clave: Quimioprevención del cáncer; Cáncer de piel no melanoma; Cancer de pulmon; Cáncer de mama; Cáncer colonrectal.

\title{
1. Introdução
}

O câncer, condição caracterizada por elevada heterogeneidade a nível genético, fenotípico e patológico, representa um dos maiores problemas de saúde pública do mundo. Segundo dados da Organização Mundial de Saúde (OMS), a cada 6 mortes, 1 é ocasionada por câncer (“The Global Challenge of Cancer”, 2020). Até o ano de 2025, características demográficas globais preveem, anualmente, mais de 20 milhões de novos casos (Zugazagoitia et al., 2016). Nesse sentido, as estimativas voltadas ao contexto epidemiológico brasileiro reproduzem um perfil similar ao dos países desenvolvidos (Santos, 2018), tendo o câncer como segunda principal causa de morte. No que se refere ao tratamento oncológico, as principais abordagens terapêuticas são a quimioterapia, a cirurgia e a radioterapia. Apesar dos avanços crescentes, pacientes e profissionais da saúde permanecem enfrentando diversos contratempos procedentes da terapia contra o câncer (Charmsaz et al., 2019; Nurgali et al., 2018).

A quimioterapia convencional engloba diversas categorias de agentes citotóxicos. Dentre eles, destacam-se os alquilantes (e.g. ciclofosfamida, temozolomida, cisplatina, oxaliplatina), os anti-metabólitos (e.g. metotrexato, citarabina, fluorouracil, capecitabina), os antibióticos antitumorais (e.g. doxorrubicina, epirrubicina, bleomicina), os inibidores da topoisomerase (e.g. etoposídeo, irinotecano) e os estabilizadores de microtúbulos (e.g. paclitaxel) (Palumbo et al., 2013). No entanto, a grande adversidade de sua aplicação encontra-se no fato de que todo e qualquer tipo celular com alta taxa de divisão também será afetado, gerando uma série de efeitos adversos (Rejhová et al., 2018). Desse modo, a capacidade dos tecidos normais de se recuperarem dos danos da quimioterapia são fatores determinantes para a tolerância do tratamento (Palumbo et al., 2013). Além disso, estudos demonstram que a resistência adquirida representa uma questão crítica até mesmo para os tratamentos mais inovadores como as terapias-alvo-moleculares devido à aquisição gradual de anormalidades genéticas e epigenéticas nas células tumorais (Nikolaou et al., 2018).

Mesmo com eficácia limitada, tais abordagens terapêuticas contribuem para um custo superior a 60 mil dólares por indivíduo e para cada ano de vida ganho com o tratamento (Blakely et al., 2015). No que se refere ao âmbito econômico brasileiro, a aquisição de medicamentos para o tratamento do câncer representa um dos maiores custos para o Sistema Único de Saúde (SUS). Como exemplo prático, em 2017, o Instituto de Pesquisa Econômica Aplicada de Brasília, colheu informações referentes a 3.037 aquisições de quimioterápicos em hospitais filantrópicos habilitados para o tratamento do câncer pelo SUS e demonstrou um valor global de R\$1.363.733.585,8213 gastos (Arantes \& Neto, 2019). Por isso, apesar da implementação de um sistema de saúde público e universal que promova a garantia de acesso, momentos de crise política e 
econômica em conjunto com o aumento do número de diagnósticos ameaçam sua sustentabilidade (Miranda et al., 2017).

É válido lembrar, ainda, que problemas relacionados ao diagnóstico tornam o câncer difícil de ser tratado. Estima-se que desde o evento de iniciação da carcinogênese até o momento em que o tumor é passível de ser detectado, até 30 anos podem ser transcorridos e, após esse tempo, a maioria dos tumores já se encontram em estágios avançados. Para a maioria dos tipos tumorais, não há biomarcadores de detecção precoce e, para aqueles que poucos possuem, o valor preditivo é baixo, sem contar que, ao passo que a progressão tumoral acontece, esses biomarcadores se tornam obsoletos (Chakraborty \& Rahman, 2012).

Em 2014, a Agência Internacional de Pesquisa em Câncer (IARC, "International Agency for Research on Cancer") declarou que, dada a atual conjuntura, o combate ao câncer é uma guerra que não pode ser vencida apenas com o tratamento, sendo dada assim, a recomendação da necessidade de se buscar outras alternativas, como por exemplo, estratégias que se voltem para a prevenção (Maeda \& Khatami, 2018). Como alternativa frente a essa emergencialidade, surge, então, a quimioprevenção. Logo, perante a predominância do estilo de vida como fator etiológico em diversos tipos de cânceres e a recomendação em se começar a adotar uma cultura de prevenção, tem-se como objetivo, nesta revisão, elencar as principais possíveis abordagens quimiopreventivas para os tumores mais frequentes no Brasil e que possuem correlação com hábitos cotidianos adotados.

\section{Metodologia}

Para esta revisão de cunho qualitativo, cuja base metodológica seguiu os princípios de Pereira et al. (2018), foi realizado levantamento bibliográfico das publicações disponíveis nas bases da National Library of Medicine (NIH - PubMed) e Scholar Google nos últimos 20 anos. Foram também incluídos nesta revisão trabalhos anteriores a este período considerados importantes para a obtenção dos resultados aqui relatados. Utilizou-se os descritores: "chemoprevention", "cancer chemoprevention" "non melanoma skin cancer", "lung cancer", "breast cancer", e "colorectal cancer". Optou-se pela exclusão dos trabalhos não associados especificamente ao tema ou desatualizados quanto às inovações.

\section{Resultados e Discussão}

\subsection{Quimioprevenção: uma estratégia contra o câncer}

A quimioprevenção consiste na administração crônica de agentes farmacológicos com o intuito de prevenir a evolução de determinada condição patológica (Penny \& Wallace, 2015). No cenário oncológico, objetiva-se, pois, atuar impedindo, suprimindo ou revertendo os eventos de iniciação ou progressão tumoral (Steward \& Brown, 2013). Para tal prática, as moléculas a serem utilizadas devem conter grupos farmacofóricos efetivos, ser de fácil administração, apresentar baixa toxicidade, ser eficazes em doses baixas, apresentar boa biodisponibilidade e possuir uma vantajosa relação custo-benefício (Penny \& Wallace, 2015).

Estrategicamente, a quimioprevenção do câncer pode ser aplicada em níveis primário, secundário e terciário. A nível primário, intenciona-se evitar ou minimizar a ocorrência de exposições a agentes de risco em indivíduos saudáveis e, de modo complementar, aumentar a resistência do organismo frente à ação de agentes mutagênicos e carcinogênicos (De Flora \& Ferguson, 2005). O nível secundário é voltado para indivíduos em estágios pré-clínicos ou iniciais da doença, nas chamadas lesões pré-malignas (De Flora \& Ferguson, 2005). Por fim, beneficia-se da quimioprevenção terciária quem já recebeu um diagnóstico e encontra-se em fase inicial de tratamento, evitando a recidiva tumoral (Penny \& Wallace, 2015).

Assume-se que a intervenção por meio de agentes quimiopreventivos deve ocorrer, preferencialmente, durante os estágios de iniciação e promoção da carcinogênese; momentos estes que demandam um maior tempo para ocorrer, ao passo que são passíveis de ser revertidos (Koh et al., 2020). Estes mecanismos, por via de regra, estão relacionados às respostas 
antioxidantes e anti-inflamatórias, às atividades imunomoduladoras, antimicrobianas e anti-angiogênicas, às vias de proliferação e diferenciação celular, à parada do ciclo celular e indução de apoptose, às regulações epigenéticas, bem como ao aumento da expressão de enzimas de detoxificação de fase II e até mesmo à modificação da microbiota intestinal (Koh et al., 2020; Naithani et al., 2008).

Dado que um amplo espectro de moléculas pode atuar como agentes quimiopreventivos, suas principais classes, mecanismos de ação e possíveis efeitos adversos encontram-se resumidos na Tabela 1. A maioria das moléculas quimiopreventivas são derivadas do reino vegetal (Pruthi et al., 2015), de modo que a composição fitoquímica tem atraído a atenção da comunidade científica (Benetou et al., 2015). Dentre as principais classes de fitoquímicos destacam-se os polifenóis (e.g. curcumina, resveratrol, quercetina), os ácidos graxos poli-insaturados (e.g. ômega 3), os carotenoides (e.g. $\beta$-caroteno, licopeno ou luteína), as vitaminas (e.g. D, E, C e ácido fólico), os minerais (e.g. selênio, zinco e cálcio) e as fibras alimentares (Langner \& Rzeski, 2012) (Tabela 1). 
Tabela 1. Principais agentes quimiopreventivos e suas classes, tumores-alvo, mecanismos/alvos moleculares e obstáculos ao uso clínico.

\begin{tabular}{|c|c|c|c|c|c|}
\hline Classe & $\begin{array}{c}\text { Agentes } \\
\text { Representativos } \\
\end{array}$ & Tumores-alvos & Mecanismos/Alvos Moleculares & $\begin{array}{c}\text { Possíveis obstáculos à aplicação } \\
\text { clínica }\end{array}$ & Referências \\
\hline \multirow[t]{2}{*}{ Vacinas } & VHB & $\begin{array}{l}\text { Carcinoma } \\
\text { Hepatocelular. }\end{array}$ & $\begin{array}{l}\text { Inibição do processo inflamatório pela } \\
\text { indução da produção de anticorpos. }\end{array}$ & $\begin{array}{l}\text { A introdução de antígenos pode } \\
\text { resultar em autoimunidade perigosa. }\end{array}$ & Benetou et al. (2015). \\
\hline & HPV & $\begin{array}{l}\text { Câncer de vulva, } \\
\text { orofaringe, cervical, } \\
\text { anal, peniano, vaginal. }\end{array}$ & $\begin{array}{l}\text { Prevenção primária contra neoplasias e } \\
\text { lesões precursoras do câncer. }\end{array}$ & $\begin{array}{c}\text { Há risco de reação alérgica e } \\
\text { contraindicação em casos de } \\
\text { hipersensibilidade a componentes da } \\
\text { vacina. }\end{array}$ & $\begin{array}{l}\text { Benetou et al. (2015); } \\
\text { Serrano et al. (2015); } \\
\text { Borsatto et al. (2011). }\end{array}$ \\
\hline \multirow[t]{4}{*}{ NSAIDs } & Aspirina & $\begin{array}{l}\text { Carcinoma } \\
\text { hepatocelular, câncer de } \\
\text { esôfago, estômago, } \\
\text { pâncreas, colorretal, } \\
\text { pulmão, ovário. }\end{array}$ & Inibição da enzima COX-2. & $\begin{array}{l}\text { Efeitos colaterais devido a inibição da } \\
\text { atividade plaquetária desenvolvida } \\
\text { pela enzima COX-1, que pode resultar } \\
\text { em hemorragias gastrointestinais, } \\
\text { intracranianas e extracranianas. }\end{array}$ & $\begin{array}{l}\text { Benetou et al. (2015); } \\
\text { Penny \& Wallace (2015); } \\
\text { Serrano et al. (2015). }\end{array}$ \\
\hline & Ibuprofeno & $\begin{array}{l}\text { Câncer colorretal, } \\
\text { mama, cólon, próstata e } \\
\text { pulmão. }\end{array}$ & $\begin{array}{l}\text { Inibição das enzimas COX-1 e COX-2 } \\
\text { e promoção da imunidade antitumoral. }\end{array}$ & $\begin{array}{c}\text { O efeito sobre a diferenciação de } \\
\text { macrófagos se dá apenas em altas } \\
\text { doses. }\end{array}$ & $\begin{array}{l}\text { De Oliveira \& Aldrighi (2006); } \\
\text { Pennock et al. (2018). }\end{array}$ \\
\hline & Celecoxibe & Câncer colorretal. & $\begin{array}{l}\text { Inibição de COX-2 e redução da } \\
\text { recorrência de adenomas colorretal em } \\
\text { pacientes de alto risco. }\end{array}$ & $\begin{array}{l}\text { Associado ao aumento de efeitos } \\
\text { adversos em pacientes de risco. }\end{array}$ & Veettil et al. (2019). \\
\hline & Diclofenaco & Câncer colorretal. & $\begin{array}{l}\text { Inibição de COX-2, indução de } \\
\text { apoptose através da inibição de Akt e } \\
\text { ação antiproliferativa através da } \\
\text { modulação da via PI3K/AKT/mTOR. }\end{array}$ & Citotoxicidade hepática e gástrica. & Arisan et al. (2018). \\
\hline SERMs & $\begin{array}{l}\text { Tamoxifeno } \\
\text { Raloxifeno } \\
\text { Lasofoxifeno } \\
\text { Arzoxifeno } \\
\text { Ospemifeno }\end{array}$ & Câncer de mama. & $\begin{array}{c}\text { Ação antiestrogênica e alteração na } \\
\text { transcrição de genes regulados por } \\
\text { estrogênios. }\end{array}$ & $\begin{array}{l}\text { Aumento da incidência de eventos } \\
\text { tromboembólicos. Há a associação do } \\
\text { uso do tamoxifeno e azoxifeno com o } \\
\text { aumento no risco de câncer de } \\
\text { endométrio. O raloxifeno e azoxifeno } \\
\text { estão associados ao risco de doenças } \\
\text { cardiovasculares. }\end{array}$ & $\begin{array}{c}\text { De Oliveira \& Aldrighi (2006); } \\
\text { Serrano et al. (2015); } \\
\text { Vogel (2014); } \\
\text { Cummings et al. (2011). }\end{array}$ \\
\hline
\end{tabular}




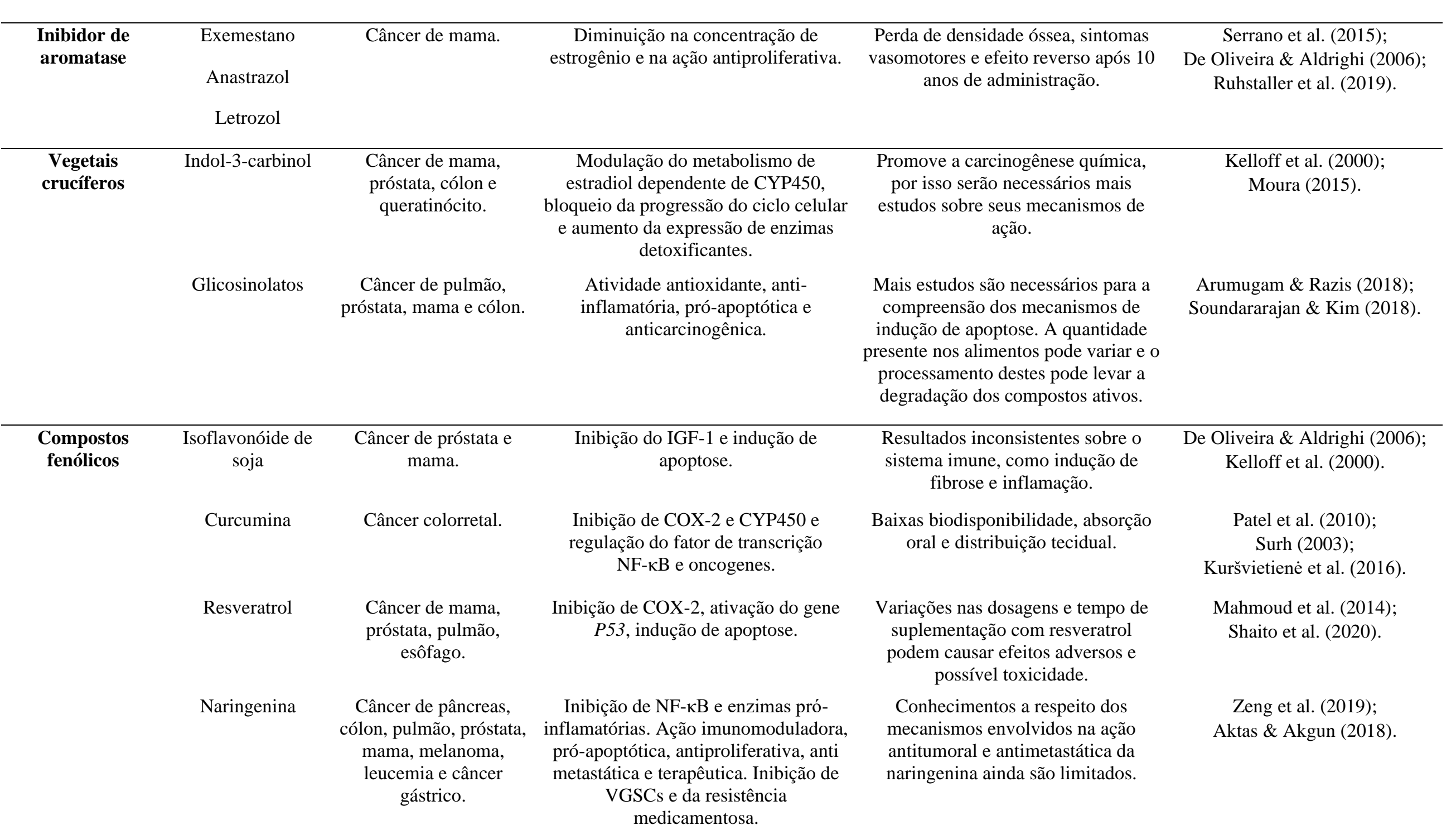


Crisina próstata, fígado e pele.

Quercetina

Tumores gástricos,

câncer de pulmão,

próstata e colorretal
Câncer de mama, cólon,
Atividade antioxidativa, antiproliferativa, pró-apoptótica, anticarcinogênica e potencialização do efeito antitumoral de quimioterápicos.

Ação antiproliferativa e antioxidante, inibição de angiogênese e proliferação

$$
\text { celular. }
$$

Crisina tem uma baixa

biodisponibilidade.

A quercetina só desempenha efeito quimioprotetor quando associada a uma elevada ingestão de frutas. Caso contrário, pode haver indução de carcinogênese.

$\begin{array}{rr}\text { Carotenóides } & \text { Licopeno } \\ \text { Luteína } \\ \\ \beta \text {-caroten }\end{array}$

Câncer de pulmão,
próstata, fígado e oral.

Câncer de mama.

Câncer de mama, cabeça, pescoço, cólon,

bexiga e pele.

\section{Ação antioxidante e inibição da} proliferação de células KB-1.

Atividade antiproliferativa e próapoptótica a partir do aumento da expressão de Bax e diminuição de Bcl-

2. Ativação do gene $P 53$ e aumento da expressão de $H S P 60$

Diminuição da expressão de proteínas anti-apoptóticas, inibição da ativação de Akt e ERK1/2.
Pode haver indução de carcinogênese por outras vias.

A ingestão de luteína associada a zeaxantina pode promover risco para

o desenvolvimento do cânce colorretal.

Aumento no risco de desenvolvimento de câncer de pulmão em fumantes.
Kasala et al. (2015).

Wu et al. (2019); Silva \& Naves (2001)

Gomes (2007).

Gong et al. (2018);

Kim et al. (2019).

Gong et al. (2018); Shree et al. (2017).

\begin{tabular}{|c|c|c|c|}
\hline \multirow[t]{4}{*}{ Vitaminas } & Vitamina E & Câncer de próstata, oral. & $\begin{array}{l}\text { Ação detoxificante e antioxidante, } \\
\text { prevenindo a peroxidação de lipídeos. }\end{array}$ \\
\hline & Vitamina A & $\begin{array}{l}\text { Câncer de bexiga, } \\
\text { mama, estômago, oral, } \\
\text { pele, cólon e reto. }\end{array}$ & Ação antioxidante. \\
\hline & Vitamina D & Câncer colorretal. & $\begin{array}{l}\text { Indução de diferenciação celular, ação } \\
\text { anti-inflamatória, antiproliferativa, } \\
\text { antimetastática e pró-apoptótica. }\end{array}$ \\
\hline & Vitamina $\mathrm{C}$ & $\begin{array}{l}\text { Câncer de estômago, } \\
\text { oral, cólon e reto }\end{array}$ & $\begin{array}{c}\text { Ação antioxidante, detoxificante e } \\
\text { inibição da formação de nitrosaminas } \\
\text { no estômago. }\end{array}$ \\
\hline
\end{tabular}

\section{A administração simultânea das \\ vitaminas E e C pode causar \\ genotoxicidade pela formação de radicais livres. \\ Há efeitos controversos pela utilização das vitaminas A e E associadas. \\ A suplementação com vitamina $\mathrm{D}$ com ou sem cálcio não exerce efeito protetor para o câncer de mama.}

Efeito dose-dependente e em altas doses gera citotoxicidade em linfócitos humanos.
Benetou et al. (2015);

Silva \& Naves (2001).

Silva \& Naves (2001)

Benetou et al. (2015).

Sutherland et al. (2020);

Kelloff et al. (2000);

Benetou et al. (2015).

Benetou et al. (2015);

Nepomuceno (2005);

Silva \& Naves (2001) 
Ácido Fólico

Câncer de laringe, mama e colorretal.

Câncer de esôfago, pâncreas, mama, colorretal e gástrico.
Manutenção da estabilidade e reparo da cromatina. Regulação de genes promotores a partir da metilação do

DNA. Atividade pró-apoptótica e antiangiogênica a partir da inibição de EGFR.

Ação anti-inflamatória através da ativação da resposta mitogênica de linfócitos.
A administração do ácido fólico associado à vitamina B12 está relacionada ao aumento no risco de desenvolvimento do câncer colorretal. Altas quantidades de ácido fólico promovem a promoção do câncer

O efeito anticarcinogênico de vitamina B6 é dose-dependente, sendo necessário em altas

$$
\text { quantidades. }
$$

Marques \& Neves (2013); Araújo et al. (2016);

Benetou et al. (2015);

Araghi et al. (2019);

Mesolella et al. (2017);

Ströhle et al. (2005);

Kim et al. (2019).

Ueland et al. (2017);

Mocellin et al. (2017)

\begin{tabular}{cc}
\hline Fibras & Celulose, \\
alimentares & Hemicelulose, \\
& Pectinas, Gomas e \\
& Mucilagens.
\end{tabular}

Câncer de intestino e

colorretal.

Mucilagens.

\begin{tabular}{|c|c|c|c|}
\hline $\begin{array}{l}\text { Probióticos/ } \\
\text { Isolados de } \\
\text { Microorganismos }\end{array}$ & Lactobacilos & Câncer de cólon. & $\begin{array}{c}\text { Ativação do sistema autoimune e } \\
\text { diminuição da produção de citocinas } \\
\text { pró-inflamatórias como interleucina } 2 \text {, } \\
\text { TNF- } \alpha \text { e interferon- } \gamma \text {. }\end{array}$ \\
\hline
\end{tabular}

Bifidobactérias

Inibição do crescimento e proliferação
celular através da produção de ácido
butírico. Evita alta exposição da
mucosa gastrointestinal às fezes e aos
carcinógenos.
Ativação do sistema autoimune e
diminuição da produção de citocinas
pró-inflamatórias como interleucina 2,
TNF- $\alpha$ e interferon- $\gamma$.

É necessário o controle da ingestão de fibras, pois estas podem competir pela absorção com outros nutrientes, favorecendo a excreção destes.

A disbiose intestinal causa alteração na quantidade e na composição de lactobacilos, o que pode favorecer a multiplicação de patógenos. Podem
Macedo et al. (2012). haver efeitos adversos em indivíduos imunocomprometidos ou susceptíveis a alérgenos.
Redução das enzimas $\beta$-glucuronidase e nitroredutase, remoção de carcinógenos pelas fezes. Atividade anti-inflamatória.
Assim como para lactobacilos, disbiose intestinal causa alteração nas bifidobactérias. Efeitos adversos também podem ser observados em imunocomprometidos.

\section{Denipote et al. (2010) \\ Maia et al. (2018);}

Vandenplas et al. (2015).

Denipote et al. (2010);

Maia et al. (2018);

Vandenplas et al. (2015). 


\begin{tabular}{|c|c|c|c|c|c|}
\hline \multirow[t]{2}{*}{ Prebióticos } & FOS & Câncer de cólon. & $\begin{array}{l}\text { Promove a redução de toxinas e } \\
\text { carcinógenos e aumento da produção } \\
\text { de imunoestimulantes que } \\
\text { desenvolvem ação antitumoral. }\end{array}$ & $\begin{array}{l}\text { A quantidade de FOS presente nos } \\
\text { alimentos é significativamente baixa } \\
\text { para exercer seu efeito como } \\
\text { prebiótico. O efeito bifidogênico não } \\
\text { é duradouro. }\end{array}$ & Denipote et al. (2010). \\
\hline & Inulina & Câncer de cólon. & $\begin{array}{l}\text { Promove a modificação da microbiota } \\
\text { do cólon levando à diminuição do pH } \\
\text { através da fermentação, bem como à } \\
\text { supressão de criptas aberrantes. }\end{array}$ & $\begin{array}{c}\text { Doses de inulina e FOS acima de } 10 \mathrm{~g} \\
\text { diárias desencadeiam efeitos } \\
\text { colaterais aos indivíduos. }\end{array}$ & $\begin{array}{l}\text { Maia et al. (2018); } \\
\text { Galdino (2017). }\end{array}$ \\
\hline \multirow[t]{3}{*}{$\begin{array}{l}\text { Compostos } \\
\text { Selênicos }\end{array}$} & Selênio & $\begin{array}{l}\text { Câncer de mama, } \\
\text { esôfago, colorretal, } \\
\text { bexiga, próstata, pele e } \\
\text { câncer gástrico. }\end{array}$ & Ação antioxidante e pró-apoptótica. & $\begin{array}{c}\text { Níveis elevados de selênio sérico } \\
\text { apresentaram eficácia na prevenção } \\
\text { do câncer. No entanto, a alta } \\
\text { exposição ao selênio pode ter efeitos } \\
\text { diferentes em tipos específicos de } \\
\text { câncer. }\end{array}$ & Cai et al. (2016). \\
\hline & $\mathrm{p}-\mathrm{XSC}$ & $\begin{array}{l}\text { Câncer de pulmão, } \\
\text { intestino e colorretal. }\end{array}$ & $\begin{array}{l}\text { Inibição do estresse oxidativo, } \\
\text { modulação de } \beta \text {-catenina e COX-2 e } \\
\text { ação pró-apoptótica. }\end{array}$ & $\begin{array}{c}\text { Em altas doses, pode exercer estímulo } \\
\text { ao crescimento tumoral ao ser } \\
\text { metabolizado. }\end{array}$ & $\begin{array}{l}\text { Collery (2018); } \\
\text { El-Bayoumy et al. (2002); } \\
\text { Rao \& Rao (1998). }\end{array}$ \\
\hline & Selenometionina & Câncer de pulmão. & Ação antioxidante e pró-apoptótica. & $\begin{array}{l}\text { O efeito protetor é dose-dependente } \\
\text { porém, em altas concentrações, pode } \\
\text { ser revertido a pró-oxidantes. }\end{array}$ & $\begin{array}{l}\text { Spallholz (2019); } \\
\text { Collery (2018). }\end{array}$ \\
\hline $\begin{array}{l}\text { Eicosanóides/ } \\
\text { Análogos de } \\
\text { Eicosanóides }\end{array}$ & Iloprosta & $\begin{array}{l}\text { Câncer de pulmão e } \\
\text { ovário. }\end{array}$ & $\begin{array}{l}\text { Inibição de COX-2 e ativação de } \\
\text { PPAR } \gamma \text {. Atividade antiproliferativa e } \\
\text { antimetastática através da modulação } \\
\text { do receptor de membrana IP e de } \\
\text { MMPs. }\end{array}$ & $\begin{array}{l}\text { PPAR } \gamma \text { pode estimular a metástase de } \\
\text { tumores iniciais. }\end{array}$ & $\begin{array}{l}\text { New \& Keith (2018); } \\
\text { Ahn et al. (2018). }\end{array}$ \\
\hline Retinóides & Isotretinoína & $\begin{array}{c}\text { Leucemia e } \\
\text { neuroblastoma. }\end{array}$ & $\begin{array}{c}\text { Aumento da atividade de proteínas } \\
\text { pró-apoptóticas como FoxO, TRAIL, } \\
\text { IGFBP3 e NGAL. }\end{array}$ & $\begin{array}{c}\text { O tratamento com isotretinoína está } \\
\text { atrelado a efeitos adversos como } \\
\text { teratogenicidade, alterações } \\
\text { mucocutâneas, inflamações e } \\
\text { depressão. }\end{array}$ & Melnik (2017). \\
\hline
\end{tabular}


Acitretina

Câncer de pele não melanoma.

Tretinoína

Câncer de pele

Aminoácidos

Arginina

Câncer de cólon, pâncreas e linfoma.
Ação imunomoduladora, próapoptótica, antiproliferativa e modulação do ciclo celular.

Ação terapêutica para queratoses actínicas, prevenindo o câncer de células escamosas.

Atividade antiproliferativa e próapoptótica.

A administração em altas doses pode causar efeitos adversos como

descamação da pele e alterações no

$$
\text { cabelo. }
$$

O uso de tretinoína está associado a efeitos adversos como queimação, prurido, eritema e descamação.

Apesar dos efeitos protetores, a

arginina é essencial para o crescimento de células tumorais.

Substratos metilados da arginina estão

relacionados ao desenvolvimento dos tumores de mama, bexiga, pulmão,

colorretal, próstata e linfoma.

\begin{tabular}{|c|c|c|c|c|c|}
\hline $\begin{array}{l}\text { Inibidor } \\
\text { irreversível de } \\
\text { ODC }\end{array}$ & DFMO & $\begin{array}{l}\text { Câncer de pele, cólon, } \\
\text { tumor gástrico, } \\
\text { pancreático e glioma. }\end{array}$ & $\begin{array}{c}\text { Ação antiproliferativa, pró-apoptótica } \\
\text { através da modulação de Bax, Bad e } \\
\text { Bcl-2. }\end{array}$ & $\begin{array}{c}\text { O tratamento prolongado com DFMO } \\
\text { está associado à toxicidade } \\
\text { gastrointestinal e sanguínea, fadiga, } \\
\text { náusea e diarreia. }\end{array}$ & Alexiou et al. (2017). \\
\hline \multirow[t]{2}{*}{ Chás } & Chá-preto & $\begin{array}{l}\text { Câncer de pâncreas, } \\
\text { próstata, fígado, ovário, } \\
\text { cólon e oral. }\end{array}$ & $\begin{array}{l}\text { Ação antimutagênica, antioxidante, } \\
\text { antiproliferativa e pró-apoptótica. }\end{array}$ & $\begin{array}{l}\text { Os efeitos do chá-preto em humanos } \\
\text { ainda são incertos. Altas quantidades } \\
\text { foram observadas como fator de risco } \\
\text { para o câncer de mama. }\end{array}$ & Singh et al. (2017). \\
\hline & Chá-verde & $\begin{array}{l}\text { Câncer de endométrio, } \\
\text { esôfago, pulmão, pele, } \\
\text { pâncreas, fígado, } \\
\text { próstata, bexiga, mama } \\
\text { e câncer oral. }\end{array}$ & $\begin{array}{c}\text { Atividade antioxidante, } \\
\text { antimutagênica, pró-apoptótica, } \\
\text { antiproliferativa, alteração do ciclo } \\
\text { celular e modulação da resposta imune. }\end{array}$ & $\begin{array}{l}\text { A ação antioxidante demonstra ser } \\
\text { efetiva apenas em casos de estresse } \\
\text { oxidativo excessivo. As dosagens } \\
\text { clínicas seguras e efetivas ainda são } \\
\text { desconhecidas. }\end{array}$ & $\begin{array}{c}\text { Singh et al. (2017); } \\
\text { Zhou et al. (2019); } \\
\text { Shirakami \& Shimizu (2018). }\end{array}$ \\
\hline $\begin{array}{l}\text { Ácido graxo poli- } \\
\text { insaturado }\end{array}$ & Ômega-3 & $\begin{array}{l}\text { Câncer de mama e } \\
\text { mieloma múltiplo. }\end{array}$ & $\begin{array}{l}\text { Ação anti-inflamatória a partir da } \\
\text { redução de citocinas pró-inflamatórias } \\
\text { e de NF- } \mathrm{BB} \text {; atividade pró-apoptótica. }\end{array}$ & $\begin{array}{l}\text { Não há referência de ingestão } \\
\text { dietética estabelecida. Efeitos } \\
\text { adversos como diarreia, gases e } \\
\text { dispepsia podem ocorrer. }\end{array}$ & $\begin{array}{c}\text { Fabian et al. (2015); } \\
\text { Freitas \& Campos (2019). }\end{array}$ \\
\hline
\end{tabular}

Koh et al. (2019);

Hardin \& Mydlarski (2010).

Geng et al. (2009).

Poulard et al. (2016)

Szende et al. (2001).

(2)




\begin{tabular}{|c|c|c|c|c|c|}
\hline Alcalóides & Piperina & $\begin{array}{l}\text { Câncer de cólon, mama, } \\
\text { próstata, ovário, } \\
\text { pulmão, osteosarcoma, } \\
\text { melanoma e } \\
\text { fibrosarcoma. }\end{array}$ & $\begin{array}{l}\text { Atividade antiproliferativa a partir da } \\
\text { modulação de checkpoints, anti- } \\
\text { inflamatória, antiangiogênica, } \\
\text { antimetastática e pró-apoptótica. } \\
\text { Inibição da resistência terapêutica e } \\
\text { aumento da biodisponibilidade de } \\
\text { quimioterápicos. }\end{array}$ & $\begin{array}{l}\text { Piperina possui uma baixa } \\
\text { biodisponibilidade. }\end{array}$ & Zadorozhna et al. (2019). \\
\hline Mucolíticos & N- acetilcisteína & Câncer de cólon e oral. & $\begin{array}{l}\text { Ação anti-inflamatória a partir da } \\
\text { inibição de NF- } \kappa \text { B e modulação de } \\
\text { citocinas pró-inflamatórias, } \\
\text { antioxidante, antiangiogênica e } \\
\text { antimetastática. }\end{array}$ & $\begin{array}{l}\text { Há uma baixa biodisponibilidade oral, } \\
\text { no entanto, pode haver náusea, } \\
\text { vômito, dor de cabeça, diarreia, dor } \\
\text { epigástrica, fadiga, constipação e } \\
\text { erupção cutânea. }\end{array}$ & $\begin{array}{l}\text { Millea (2009); } \\
\text { Pei et al. (2018). }\end{array}$ \\
\hline ITCs & Sulforafano & $\begin{array}{l}\text { Câncer de bexiga, } \\
\text { próstata e osteosarcoma. }\end{array}$ & 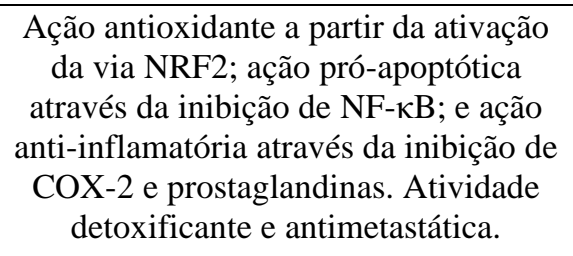 & $\begin{array}{l}\text { A ação protetora do sulforafano é } \\
\text { dose-dependente. A ação } \\
\text { detoxificante pode inibir o efeito do } \\
\text { quimioterápico quando administrada } \\
\text { em conjunto. }\end{array}$ & $\begin{array}{c}\text { Leone et al. (2017); } \\
\text { Bauman et al. (2016). }\end{array}$ \\
\hline \multirow[t]{3}{*}{ Estatinas } & Atorvastatina & $\begin{array}{l}\text { Câncer de mama e } \\
\text { próstata. }\end{array}$ & $\begin{array}{l}\text { Inibiçãa de HMG-CoA redutase, } \\
\text { indução de autofagia, ação } \\
\text { antiangiogênica, pró-apoptótica, } \\
\text { antiproliferativa e antimetastática. } \\
\text { Aumento da radiossensibilidade no } \\
\text { tratamento do câncer de próstata. }\end{array}$ & $\begin{array}{c}\text { São necessárias altas doses para } \\
\text { atingir efeito antiproliferativo em } \\
\text { monoterapia, o que acarretaria efeitos } \\
\text { adversos. }\end{array}$ & $\begin{array}{l}\text { Barbalata et al. (2020); } \\
\text { Hu et al. (2018); } \\
\text { Chen et al. (2017). }\end{array}$ \\
\hline & Cerivastatina & $\begin{array}{c}\text { Câncer de mama e } \\
\text { pâncreas. }\end{array}$ & $\begin{array}{c}\text { Inibiç̧ão de HMG-CoA redutase e } \\
\text { indução de senescência, ação } \\
\text { antiproliferativa, antiangiogênica e } \\
\text { pró-apoptótica. }\end{array}$ & $\begin{array}{l}\text { A combinação de cerivastatina com } \\
\text { os quimioterápicos doxorrubicina e } \\
\text { cisplatina demonstrou potencialização } \\
\text { dos efeitos citotóxicos. }\end{array}$ & Kozar et al. (2004). \\
\hline & Fluvastatina & $\begin{array}{l}\text { Câncer de pulmão, } \\
\text { mama }\end{array}$ & $\begin{array}{c}\text { Ação antimetastática, } \\
\text { imunomodulatória, antiinflamatória, } \\
\text { inibição de HMG-CoA redutase, } \\
\text { indução de autofagia e ativação do } \\
\text { P53. }\end{array}$ & $\begin{array}{c}\text { A ação antimetastática da fluvastatina } \\
\text { é dependente da quantidade de P53 } \\
\text { nas células cancerosas. }\end{array}$ & Yang et al. (2017). \\
\hline
\end{tabular}


Pravastatina

Câncer de pulmão, ovário, gástrico e leucemia.

Lovastatina

Câncer colorretal, de mama e ovário.
Inibição de HMG-CoA redutase e ação antiproliferativa a partir da inibição de $R A S$

Bloqueio de vias de síntese de colesterol e de proliferação celular; ativação de vias celulares de morte por apoptose.
Podem ocorrer dores musculares. O efeito protetor não ocorre para

pacientes com tumores avançados.

Possibilidade de interação com o

tratamento quimioterápico. A

pravastatina também pode induzir o

desenvolvimento tumoral ao induzir a

síntese de mevalonato.

Biodisponibilidade reduzida por

alimentos, por vezes abaixo de $50 \%$,

com extensa metabolização de

primeira passagem no fígado.

Náusea, dor abdominal, insônia,

dispepsia, dores de cabeça, astenia e

mialgia moderadas relatadas de

maneira associada ao tratamento.
Bujanda et al. (2016).

Di Bello et al. (2020);

Martirosyan et al. (2010);

Murakami et al. (2016);

Curran \& Goa (2003).

\begin{tabular}{|c|c|c|c|c|c|}
\hline Aminossalicilatos & Mesalazina & Câncer colorretal. & $\begin{array}{c}\text { Ação antiproliferativa a partir da } \\
\text { inibição de COX-2 e ROS, pró- } \\
\text { apoptótica }\end{array}$ & $\begin{array}{l}\text { A ação antitumoral de mesalazina é } \\
\text { demonstrada apenas em altas doses. }\end{array}$ & Stolfi et al. (2012). \\
\hline
\end{tabular}

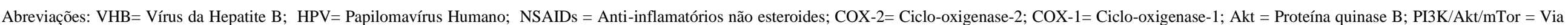

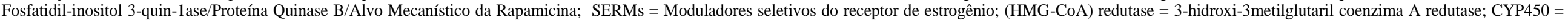

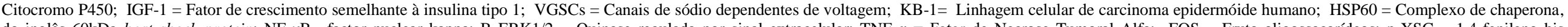

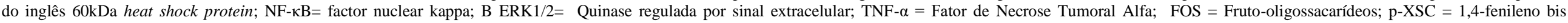

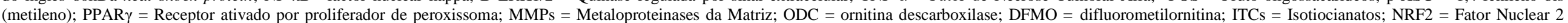
relacionado ao eritroide 2; RAS = Oncogene do vírus do sarcoma de ratos; ROS = Espécies Reativas de Oxigênio; EGFR= receptor do fator de crescimento epidérmico.

Fonte: Autores (2021). 
É importante destacar que agentes etiopatogênicos que envolvem danos no DNA, estresse oxidativo e inflamação crônica, por exemplo, estão presentes em várias outras doenças crônicas além do câncer. Nesse sentido, não só fatores de risco podem ser compartilhados, mas também, estratégias de prevenção (De Flora \& Ferguson, 2005). Desse modo, depreende-se que a implementação desses agentes em larga escala tende a ser capaz de extrapolar a ação antitumoral desejada, onde um grupo de indivíduos muito maior pode ser beneficiado.

Como resultado da busca por agentes quimiopreventivos e câncer, a seguir, encontram-se descritas notáveis abordagens quimiopreventivas para alguns dos tumores mais comuns no Brasil. Segundo Estatísticas de Câncer (INCA, 2021), o tipo de câncer mais incidente em território brasileiro é o câncer de pele não melanoma para ambos os sexos. Em seguida, encontram-se os tumores de próstata, pulmão, colorretal e estômago em homens e os tumores de mama, colorretal, colo do útero e pulmão em mulheres.

\subsubsection{Câncer de pele não melanoma}

O câncer de pele não melanoma (CPNM) é resultante de alterações em células do tecido epitelial queratinizado e representa o tipo tumoral mais frequentemente diagnosticado. A exposição crônica à radiação ultravioleta e o tipo de pele atuam como fatores determinantes na iniciação dessa neoplasia (Dubas \& Ingraffea, 2013; Lee \& Miller, 2009; Linares et al., 2015).

A ação como carcinógeno completo realizada pela radiação ultravioleta é dada pela ação dos raios UVA e UVB (D’Orazio et al., 2013; Hussein, 2005). A radiação UVB atua diretamente nas bases nucleotídicas do DNA, proporcionando a formação de fotoprodutos, como os dímeros de pirimidina ciclobutano e do 6-4 pirimidina-pirimidona (Hussein, 2005).

Tendo a exposição solar como principal fator etiológico na patogênese do câncer de pele, o padrão universal de prevenção primária e secundária consiste em adotar medidas de proteção solar. Não obstante, pacientes pertencentes a grupos de risco podem lançar mão de medidas preventivas adicionais (Soltani-Arabshahi \& Tristani-Firouzi, 2013):

- Retinóides (vitamina A): apresentam um vasto potencial como agentes quimiopreventivos e quimioterapêuticos, dado sua capacidade de inibir a proliferação celular em diferentes estágios da carcinogênese (Das et al., 2014). Os retinóides desencadeiam a parada do ciclo celular em G1 e inibem a expressão de ciclinas atuantes nesta fase, modulam vias relacionadas à apoptose (por regular a atividade de caspases) e inibem a regulação positiva do fator de transcrição AP-1 em vias de proliferação e transformação celular. Modelos experimentais de carcinogênese cutânea in vivo evidenciam que a via de sinalização B-Raf/Mek/Erk representa um importante alvo molecular dos retinóides (Prado et al., 2011).

Diferentes ensaios clínicos têm explorado a ação quimiopreventiva dos retinóides na carcinogênese cutânea (Wright et al., 2006). A administração crônica de isotretinoína (dose de $1,5 \mathrm{mg} / \mathrm{kg} / \mathrm{d}$ ) em pacientes com carcinoma basocelular (CBC) demonstrou acarretar uma diminuição no surgimento de novos tumores. Porém, quando administrada em dose mais alta (3,1 $\mathrm{mg} / \mathrm{kg} / \mathrm{d}$ ), por 8 meses, não demonstrou eficácia e os pacientes apresentaram reações adversas de moderadas a severas (Peck et al., 1982, 1988; Soltani-Arabshahi \& Tristani-Firouzi, 2013). Esse efeito, chamado "Janus" é característico de algumas moléculas, conhecidas por apresentarem efeitos protetores em doses baixas, e em doses altas gerar toxicidade (Nogueira \& Rocha, 2010). George e colaboradores (2002) avaliaram a eficácia quimiopreventiva oral da acitretina em 23 pacientes receptores de aloenxerto renal e com histórico de lesões de CPNM. Apesar dos efeitos colaterais limitantes, de modo que 39\% dos pacientes deixaram o estudo, os resultados demonstraram diminuição da incidência de carcinoma de células escamosas da pele (CCE) (George et al., 2002).

Os efeitos adversos decorrentes do uso de retinóides sistêmicos evidenciam que o emprego dessa classe de medicamentos deve ser dependente de um controle rigoroso. Nesse sentido, o objetivo proveniente de seu emprego quimiopreventivo deve ser apenas com o intuito de que o número de tumores chegue a um nível que possa ser melhor 
manejado por posteriores abordagens (Cajueiro et al., 2014; Soltani-Arabshahi \& Tristani-Firouzi, 2013). Em sua forma tópica, representam uma alternativa adicional por causarem apenas reações locais (Ianhez et al., 2013). Nessa lógica, Ianhez e colaboradores (2019) compararam 2 tratamentos: a administração oral de $10 \mathrm{mg} / \mathrm{d}$ de isotretinoína com o uso de tretinoína em creme a $0,05 \%$ em pacientes com queratose actínica submetidos a crioterapia. Ambos os tratamentos reduziram, em média, $28 \%$ das lesões, além de proporcionarem uma redução na expressão das proteínas p53 e Bax, e um aumento na expressão da proteína anti-apoptótica Bcl-2 (Ianhez et al., 2019).

- Anti-inflamatórios não-esteroidais: os anti-inflamatórios não-esteroidais (AINES) têm despertado interesse como agentes quimiopreventivos devido à capacidade de inibição da Ciclo-oxigenase-2 (COX-2), enzima que, quando hiperexpressa, favorece a progressão neoplásica através da participação em processos como proliferação celular, angiogênese e atividade antiapoptótica (Chen et al., 2013; Reinau et al., 2015).

Butler e colaboradores (2005) demonstraram que indivíduos com lesões cancerosas e usuários menos regulares de AINES apresentavam frequência de queratoses actínicas maior do que os que faziam uso regular (Butler et al., 2005). Similarmente, Elmets e colaboradores (2010), após 11 meses de tratamento com 200mg de celecoxibe 2 vezes ao dia, demonstraram que os indivíduos tratados apresentavam menos tumores cutâneos quando comparados aos que receberam placebo, indicando ação quimiopreventiva de um AINE em pacientes com CCE e CBC e com risco de evolução para CPNM (Elmets et al., 2010). Outros trabalhos têm explorado o uso tópico de gel de diclofenaco a 3,0\% no tratamento de queratoses actínicas, o que tem apresentado boa tolerância por parte dos pacientes (Nelson et al., 2004; Rivers et al., 2002).

- T4 endonuclease V (T4N5): é uma enzima originalmente isolada de uma cepa de Escherichia coli infectada com bacteriófago T4 capaz de reparar dímeros de pirimidina ciclobutano induzidos pela radiação UV por meio da excisão de bases em duas etapas, evitando, assim, eventos mutagênicos nos estágios iniciais (Camp et al., 2011; Prado et al., 2011). Em modelo animal, lipossomos contendo T4N5 mostraram-se aptos a penetrar o estrato córneo e a adentrar os queratinócitos basais, aumentando a atividade do sistema de reparo nessas células (Yarosh et al., 1994). Em 2001, um estudo clínico testou o efeito de uma loção contendo lipossomos com T4N5 em pacientes com xeroderma pigmentoso e uma diminuição significativa (68\% e 30\%) no surgimento de novas lesões actínicas e de CBCs, respectivamente, foi demonstrada (Yarosh et al., 2001).

- Difluorometilornitina (DFMO): é um inibidor irreversível da ornitina descarboxilase (ODC), cujo gene além de ser classificado como um oncogene, é, também, alvo de vários outros oncogenes como MYC e RAS, os quais apresentam vias de sinalização amplificadas em vários tipos de câncer. Além disso, ODC é uma enzima chave na biossíntese das poliaminas, as quais estão envolvidas em vias essenciais de sobrevivência celular (Alexiou et al., 2017; Damiani \& Wallace, 2018). Considerando que a radiação UV se mostra um agente potente na indução da atividade da ODC, e no subsequente desenvolvimento tumoral, o emprego de DFMO como agente quimiopreventivo para pacientes com alto risco de CPNM tem sido investigado e sustentado por resultados obtidos através de modelo animal. Fischer e colaboradores (2001) demonstraram uma proporção de tumores $75 \%$ menor que o grupo controle, e ainda uma ação protetora tanto antes quanto depois do aparecimento dos tumores, mesmo sob um regime de tratamento em doses baixas (Fischer et al., 2001; Jeter et al., 2016; Prado et al., 2011).

Resultados positivos também já foram obtidos de testes clínicos. Einspahr e colaboradores (2002) constataram uma diminuição de 23,5\% no número de lesões actínicas proveniente do uso tópico de DFMO, tal qual para o número de células positivas para p53 (Einspahr et al., 2002). Quanto às evidências de toxicidade em humanos, um ensaio de fase I demonstrou ótima tolerância por parte de pacientes transplantados (Carbone et al., 2001).

- Polifenóis do chá verde: os mecanismos preventivos do chá verde englobam atividades de redução de estresse oxidativo e de processos inflamatórios, de modulação do ciclo celular e de sistemas de reparo do DNA, inibição de vias de sinalização por meio de receptores tirosinas-cinase além do controle da modificação epigenética induzida pela radiação UV. O 
chá verde é rico em compostos polifenólicos antioxidantes denominados epicatequinas, sendo a epigalocatequina-3-galato (EGCG) o principal quimiopreventivo responsável pelos efeitos (Katiyar \& Elmets, 2001; Sharma et al., 2018; Shirakami \& Shimizu, 2018). Seu consumo regular foi associado à redução do risco de desenvolvimento de CPNM, uma vez que dados epidemiológicos mostram menor risco de desenvolvimento de CCE em indivíduos que habitualmente bebem o chá. Além disso, essa relação se torna mais intensa à medida que se aumenta o tempo de consumo (Rees et al., 2007). Evidências científicas fundamentam o uso do chá verde na quimioprevenção primária e terciária do câncer. Nesta última, por sua vez, para fins de efeito sinérgico, o emprego é sugerido em associação à quimioterapia corriqueira, como terapia adjuvante (Fujiki et al., 2018; Musial et al., 2020).

Células epidérmicas humanas com diferenciação normal de queratinócitos, quando tratadas com EGCG previamente à exposição UVB, apresentam uma redução de 66 a $80 \%$ nos níveis de $\mathrm{H}_{2} \mathrm{O}_{2}$. Concomitante a isso, o tratamento prévio com EGCG revela-se capaz de inibir a fosforilação das proteínas ERK1/2, JNK e p38, sugerindo sua participação na atenuação de patologias cutâneas influenciadas por estresse oxidativo e pela ativação da via das MAPs cinases em humanos (Katiyar et al., 2001).

A capacidade de EGCG de inibir a carcinogênese cutânea também já foi explorada em modelos experimentais murinos (Gensler et al., 1996; Lu et al., 2005; Mantena et al., 2018). Camundongos SKH-1, expostos cronicamente aos raios UVB e quando tratados topicamente com EGCG, obtiveram uma redução de 55\% e 66\% dos tumores benignos e malignos de pele, respectivamente. Resultados de imuno-histoquímica demonstraram aumento dos níveis de células positivas para caspase 3 em $72 \%$ para os tumores benignos e em $56 \%$ para os tumores de células escamosas, revelando que o efeito protetor pode envolver a ativação de vias apoptóticas em células cancerosas e/ou potencialmente cancerosas (Lu et al., 2002).

\subsubsection{Câncer de pulmão}

Mundialmente, o câncer de pulmão representa a principal causa de mortalidade por câncer, caracterizando um quarto de todas as mortes. Em 2017, causou mais mortes que os tumores de mama, de próstata, da região colorretal e cerebral juntos (National Lung Screening Trial Research Team, 2019; Siegel et al., 2020). Além da notável incidência, somente 8,8\% dos casos de câncer de pulmão no estado de São Paulo são diagnosticados de forma precoce, dificultando a efetividade de terapias curativas, visto que a doença já se encontra localmente avançada ou metastática (estágios III e IV) no momento do diagnóstico. Mais dificultosas ainda são as limitações que o sistema de saúde brasileiro enfrenta em relação às estratégias de acesso e de incorporação dos métodos de avaliação diagnóstica e de terapias específicas para câncer de pulmão (Araujo et al., 2018).

Intervir na prevenção de modo a diminuir o seu risco ou, até mesmo, impedir seu desenvolvimento, acarretaria em um positivo impacto na saúde (Greenberg et al., 2013). Nessa perspectiva, a cessação do tabagismo configura a base da prevenção do câncer de pulmão representando, atualmente, a única medida comprovadamente eficaz na redução do risco de desenvolvimento deste tipo de tumor. Apesar disso, ainda assim, diversos estudos têm trabalhado em prol da identificação e avaliação de moléculas que possam vir a constituir relevantes agentes quimiopreventivos contra o carcinoma pulmonar (New \& Keith, 2018).

- Iloprosta: princípio ativo do fármaco Ventavis® que imita uma substância natural do organismo conhecida como prostaciclina (PGI2), um eicosanóide com potencial de suprimir inflamação e micrometástases (Keith et al., 2002, 2004). Animais transgênicos que contavam com a hiperexpressão da PGI2 específica para os pulmões, quando comparados aos nãotransgênicos, apresentaram reduções significativas na incidência e na multiplicidade dos tumores, sugerindo a participação de PGI2 na prevenção da carcinogênese pulmonar proveniente da exposição ao tabaco (Keith et al., 2004).

Um estudo multicêntrico, duplo-cego, randomizado, de fase II e controlado por placebo, atestou o efeito protetivo proveniente do uso de iloprosta por 6 meses em ex-fumantes com atipia citológica do escarro ou com displasia endobrônquica 
(Keith et al., 2011). O resultado promissor encontrado torna viável a aplicação. Portanto, a continuação de ensaios clínicos a longo prazo deve ser estimulada para a validação do uso de iloprosta como um agente quimiopreventivo para o câncer de pulmão.

- Inibidores de leucotrienos: A enzima 5-lipoxigenase (5-LOX) também é responsável pela síntese dos eicosanóides, dentre os quais estão incluídos vários leucotrienos - mediadores lipídicos da inflamação em diferentes processos patológicos, inclusive no câncer (Moore \& Pidgeon, 2017). Acerca disso, os carcinógenos presentes no tabaco são capazes de aumentar, justamente, a expressão de 5-LOX, do leucotrieno B4 e de COX-2 (Keith, 2009).

Estudos têm investigado a inibição de receptores de leucotrienos ou a inibição da sua produção como abordagem quimiopreventiva. Os leucotrienos do tipo cisteínico representam alvos terapêuticos interessantes uma vez que, além de desencadearem processos inflamatórios, podem modular vias apoptóticas, de proliferação celular e a transcrição de genes potenciais (Tsai et al., 2016). Gunning e colaboradores (2002) relataram que os tratamentos por 13 semanas com 2 inibidores de leucotrienos, Accolate e Zilueton, evidenciaram significativas ações quimiopreventivas mediadas na fase de promoção da carcinogênese pulmonar (Gunning et al., 2002). Tsai e colaboradores (2016), por outro lado, depararam-se com efeitos protetivos também em indivíduos asmáticos, os quais aderiram ao uso de fármacos antagonistas de receptores de leucotrienos cisteínicos. A partir deste último estudo, os pacientes foram acompanhados em um ano até os possíveis desfechos: desenvolvimento de câncer, morte do indivíduo ou término do estudo. Constatou-se uma redução dose-dependente de 60 a $78 \%$ do risco de desenvolvimento de tumores, não só pulmonares (Tsai et al., 2016). Logo, o sugestivo efeito protetor proveniente dos antagonistas destes receptores, aliado aos seus perfis de segurança satisfatórios, podem facilitar o futuro emprego destes agentes em quimioprevenção do câncer (Tsai et al., 2016).

- Selênio: as atividades antitumorais exercidas pelos compostos selênicos são mediadas pelo seu efeito antioxidante decorrente da manutenção do equilíbrio redox intracelular e da proteção das células contra os danos oxidativos (Tan et al., 2019). Tais efeitos são possíveis devido às selenoproteínas (e.g glutationa peroxidases, glutationa redutase e tioredoxinas redutases) que conferem proteção direta contra o estresse oxidativo ou, de maneira indireta, através da regeneração e ativação de outros antioxidantes de baixo peso molecular como Q10, vitaminas C, E, entre outros (Collery, 2018; Fernandes \& Gandin, 2015).

El-Bayoumy e colaboradores (2002) demonstraram que a eficácia quimiopreventiva do composto organosselênico, o 1,4-fenileno bis (metileno) selenocianato (p-XSC), em carcinoma pulmonar (linhagem NCI-H460) se dá através da inibição da capacidade proliferativa e da expressão de COX-2. Ainda, a exposição prévia das células NCI-H460 a uma dose não tóxica de p-XSC, antes da inoculação em camundongos nude, contribuiu para a significativa supressão do crescimento tumoral quando comparado às células inoculadas que não foram pré-tratadas com p-XSC (El-Bayoumy et al., 2002).

Sob a perspectiva clínica, 302 pacientes com câncer de pulmão foram acompanhados por 80 meses ou até o óbito. Os dados coletados sugerem um acréscimo na sobrevida global em pacientes em tratamento para câncer de pulmão que se encontram no estágio I da doença, e com níveis séricos de selênio acima de $69 \mu \mathrm{g} / \mathrm{L}$ no momento do diagnóstico (Pietrzak et al., 2019). Além disso, as propriedades protetoras dos compostos selênicos já se demonstraram aptas a combater até mesmo os efeitos colaterais induzidos por quimioterápicos clássicos (Rao \& Rao, 1998). Rao e Rao (1998) exploraram a ação da selenometionina em camundongos tratados com cisplatina e demonstram que os níveis de uréia e creatinina foram reduzidos significativamente, indicando uma diminuição na toxicidade gerada pelo quimioterápico. A depleção da função renal, mensurada pelos níveis de depuração de creatinina e de proteinúria, demonstrou-se significativamente revertida. Esses resultados levaram a um aumento na sobrevida, sugerindo proteção da toxicidade renal induzida pelo tratamento com cisplatina (Rao \& Rao, 1998). 
Apesar de diversas evidências científicas favoráveis, muitas são ainda as hesitações em relação à aplicação dos compostos selênicos como quimiopreventivos para o câncer (Lü et al., 2016). Isso pode ser afirmado pois, apesar das propriedades antioxidantes relatadas, dependendo das concentrações empregadas, os efeitos podem ser revertidos a próoxidantes, de modo que possa haver o estímulo do crescimento tumoral (Collery, 2018).

- Polifenóis: a intervenção alimentar com polifenóis é fundamento de diversas bases científicas com o intuito de se impedir processos mutagênicos e de transformação neoplásica, bem como no propósito de se reduzir efeitos colaterais associados à quimioterapia e à radioterapia (Amararathna et al., 2016; Zhou et al., 2019).

A naringenina, por exemplo, é um flavonóide encontrado em uma variedade de frutas cítricas, como a laranjabergamota e o tomate (Salehi et al., 2019). Já demonstrou regular seletivamente e positivamente a expressão do receptor de morte 5 (DR5, "Death receptor 5") na superfície celular, favorecendo a morte por apoptose in vitro em carcinoma pulmonar de células não-pequenas A549 (Jin et al., 2011). De maneira equivalente, a quercetina, habitualmente encontrada em alcaparras, cebolas, maçãs entre outras frutas e vegetais, também demonstrou inibir a proliferação de células A549 e o crescimento dos tumores pulmonares in vivo, ambos os casos mediados por apoptose (Rauf et al., 2018; Zheng et al., 2012). A crisina, flavonóide encontrado na própolis e no mel, tem demonstrado efeito quimiopreventivo em câncer de pulmão induzido por benzo(a)pireno em camundongos Swiss, através da atenuação dos níveis de peróxidos lipídicos, do antígeno carcinoembrionário, do antígeno nuclear de proliferação celular (PCNA, "Proliferative Nuclear Cell Antigen"), de COX-2 e do fator de transcrição nuclear kappa B (NF-kB, “Nuclear Factor-kappa B”). Paralelamente, a suplementação de crisina restaurou significativamente os níveis de antioxidantes enzimáticos e não-enzimáticos para os valores próximos da normalidade (Kasala et al., 2015, 2016). O polifenol resveratrol, presente majoritariamente em uvas e no vinho tinto, também tem exibido potente ação quimiopreventiva. Monteillier e colaboradores (2018) demonstraram que camundongos tratados com uma formulação concentrada de resveratrol intranasal não só apresentaram uma diminuição de $27 \%$ e de $45 \%$ na multiplicidade e no volume tumoral, respectivamente, como também, foram vítimas de uma administração 22,5 vezes mais eficiente do que a administração oral (Monteillier et al., 2018).

Apesar de se apresentarem como promissores agentes quimiopreventivos para o câncer de pulmão, faz-se necessário avaliar a eficiência da entrega pulmonar destes compostos fenólicos, uma vez que os estudos neste campo ainda são escassos (Muller et al., 2019).

\subsubsection{Câncer de mama}

De todas as mulheres diagnosticadas com câncer, 25\% delas possuem câncer de mama (Sun et al., 2017). Por se tratar de um dos principais motivos da morte de mulheres entre os 45 e 55 anos, aliado a alta incidência, o câncer de mama retrata um sério impasse para a saúde pública, sobretudo a do Brasil (Andrade \& Andrade, 2014; Ataollahi et al., 2015). Felizmente, menos de $10 \%$ dos cânceres de mama são resultantes de mutações genéticas herdadas e, desse modo, podem ser evitados (Rojas \& Stuckey, 2016). Assim, e com base no gradativo número de evidências científicas, o uso de agentes quimiopreventivos, em pacientes com alto risco para o desenvolvimento de câncer de mama, tem ganhado forte aprovação para seus devidos empregos segundo diretrizes médicas (Ball et al., 2019).

- Moduladores seletivos do receptor estrogênico (MSREs): consiste na propriedade de ligação específica desses compostos ao receptor de estrogênio e consequente interação com coativadores ou corepressores para alterações tecidoespecíficas nos níveis de expressão gênica (Smith et al., 2014; Thiebaud \& Secrest, 2001). O primeiro MSRE aprovado como quimiopreventivo foi o tamoxifeno em 1998 com o projeto "O Ensaio de Prevenção do Câncer de Mama" ("The Breast Cancer Prevention Trial”). Este agente demonstrou acarretar diminuição do risco de câncer invasivo e não invasivo em norteamericanas em torno de 50\% (Fisher et al., 1998). 
Muitos dos estudos subsequentes, particularmente os de fase II, concentraram-se no propósito de melhoria do perfil risco-benefício desse agente e a avaliação da eficácia em doses baixas. Por conseguinte, o apanhado geral dos achados de diversos ensaios clínicos corroborou para o emprego do tamoxifeno em baixas doses para fins preventivos, uma vez que a administração de $20 \mathrm{mg} /$ dia, por exemplo, demonstrou acarretar efeito semelhante à administração de doses mais elevadas (30 a 40mg/dia) (Li et al., 2016). Após meticulosa avaliação dos riscos e benefícios por trás da aplicação deste agente, o tamoxifeno foi aprovado pelo FDA ("Food and Drug Administration") para o uso como quimiopreventivo do câncer de mama em mulheres com idade igual ou superior a 35 anos, e que apresentem risco de desenvolvimento deste tumor em 5 anos de 1,67\% ou mais (Waters et al., 2012). Através de modelos matemáticos, prevê-se que uso do tamoxifeno nessa população acarretaria em um ganho de 85 "anos de vida ajustados pela qualidade" por 1000 mulheres pós-menopausadas, somado, ainda, a uma economia de 47.580 dólares, se comparado à ausência de tratamento ao longo da vida (Noah-Vanhoucke et al., 2011).

Em 2007, para a prevenção do câncer de mama invasivo em mulheres pós-menopausadas e com menor incidência de eventos adversos como tromboembolismo e cataratas, foi aprovado pelo FDA o uso do raloxifeno. Em vista da modulação tecido-específica, o raloxifeno tem demonstrado atividade agonista responsável por efeitos protetores ósseos (De Oliveira \& Aldrighi, 2006; Goldstein et al., 2009; Smith et al., 2014).

Os diversos estudos envolvendo estes dois agentes, para fins mecanicistas, serviram de alicerce para o desenvolvimento, ao longo do tempo, de MSREs de gerações posteriores, como o lasofoxifeno, arzoxifeno, ospemifeno, etc (Smith et al., 2014).

- Inibidores de aromatase (IAs): a inibição dessa enzima tem sido utilizada em várias abordagens clínicas para o câncer de mama visto que em mulheres pós-menopausadas, a principal fonte de produção de estrogênio ocorre mediante o processo de aromatização dos andrógenos. IAs como anastrozol, letrozol e o exemestano encontram-se em testes clínicos (Ball et al., 2019). A eficácia do uso destes inibidores pode ser exemplificada pelos resultados obtidos no Estudo Internacional de Intervenção em Câncer de Mama II (IBIS-II, "International Breast Cancer Intervention Study II”). O IBIS-II foi um estudo randomizado, duplo-cego e controlado por placebo que avaliou 3.864 mulheres na pós-menopausa com alto risco de desenvolver câncer de mama, e que receberam $1 \mathrm{mg} /$ dia de anastrozol ou placebo diariamente por 5 anos. Após 131 meses, foi constatado uma redução de 49\% dos casos de câncer de mama entre as mulheres que receberam anastrozol (85 casos vs 165 casos no grupo controle). Além disso, a quimioprevenção crônica com anastrozol reduziu em 54\% os casos de câncer de mama invasivo positivos para o receptor de estrogênio (Cuzick et al., 2020). O anastrozol tem demonstrado ser mais eficaz que o tamoxifeno em mulheres na pós-menopausa com menos de 60 anos de idade, elevando-o a uma alternativa preferencial em benefício desse grupo de pacientes (Margolese et al., 2016), além de ser economicamente mais viável (Locker et al., 2007; Lux et al., 2010). Perspectivas futuras se voltam, agora, para novas possibilidades, como a combinação de IAs com agentes alvo, como os inibidores de cinases dependente de ciclina 4 e 6 (CDK, "Cyclin-Dependent Kinase") ou os inibidores da via PI3K/Akt/mTOR (Barchiesi et al., 2020).

- Outros agentes: estudos tem fornecido evidências de que vitaminas (vitamina D3, folato, vitamina B6) e micronutrientes como beta-caroteno, curcumina, piperina, sulforafano, indole-3-carbinol, quercetina, EGCG, ômega-3 entre outros, exibem atividade antitumoral e apresentam-se como uma estratégia natural para a quimioprevenção (Mokbel et al., 2019).

Na metanálise realizada por Zeng e colaboradores (2019), de um total de 23 estudos prospectivos envolvendo 41.516 casos e 1.171.048 indivíduos, foi demonstrado que a suplementação com $100 \mu \mathrm{g}$ de folato está associada a uma diminuição do risco de câncer de mama receptor hormonal negativo (Zeng et al., 2019). Quanto à ingestão de glicosinolatos presentes em vegetais crucíferos, como o brócolis e o repolho, já foi demonstrado que o consumo, por mulheres com achados mamográficos suspeitos, relaciona-se de maneira inversa à expressão da proteína Ki-67, um biomarcador de proliferação celular, no 
carcinoma ductal de mama in situ (Russo et al., 2018; Zhang et al., 2016). Já foi observado que o sulforafano, um isotiocianato formado a partir dos glicosinolatos, induz a parada do ciclo celular e a apoptose bem como inibe a proliferação, a angiogênese e a capacidade de formação de metástases em células de câncer de mama. Em células MDA-MB-231, o sulforafano causa interrupção do ciclo celular através da diminuição da expressão de ciclina A, ciclina B1 e CDC2 (Kanematsu et al., n.d.; Vanduchova et al., 2019).

Ainda, em modelos in vitro, a exposição de células de câncer de mama MCF-7 à vitamina D3 e ao resveratrol promove regulação negativa da DNA metiltransferase e regulação positiva de p21. A sugestiva regulação da maquinaria de metilação do DNA nestas células promoveu, também, a redução da metilação do promotor de PTEN, cuja perda geralmente prediz comportamentos mais agressivos e, de maneira geral, piores prognósticos em pacientes com câncer de mama (Li et al., 2017; Stefanska et al., 2012).

Outros suplementos dietéticos como com óleo de peixe, com vitamina B6 e com metionina apresentaram, também, associação com a diminuição do risco de surgimento de tumores na mama em um significativo número de mulheres pósmenopausadas (Brasky et al., 2010; Wu et al., 2013). O consumo de chá preto aparenta possuir também um apreciável efeito quimiopreventivo em tumores de mama hormônio-dependentes (Way et al., 2004). Os achados de Way e colaboradores (2004) mostram que, em decorrência da presença dos polifenóis TF-1, TF-2 e TF-3, as atividades da enzima aromatase, no ovário de animais e em placentas humanas, foram significativamente inibidas. Aliás, ao contrário do tamoxifeno, os polifenóis do chá preto apresentam potente atividade antiproliferativa em células de carcinoma de mama com resistência hormonal (Way et al., 2004).

\subsubsection{Câncer colorretal}

No ano de 2018, no Brasil, o câncer colorretal ocupou o terceiro lugar entre os tipos de tumores mais incidentes em homens ( $8,1 \%$ dos casos) e o segundo em mulheres (9,4\% dos casos), representando, no período de 2012 a 2016, um aumento de $20,89 \%$ e uma média de crescimento anual de $4,91 \%$. Frente a tais dados epidemiológicos, tal como o longo período de transição de uma lesão precursora (10 a 15 anos), reitera-se a necessidade do desenvolvimento de políticas públicas com focos preventivos primário e secundário (Gwyn \& Sinicrope, 2002; Half \& Arber, 2009; Marques et al., 2019).

Graças à progressão lenta, cerca de $70 \%$ dos casos podem ser evitados com a adoção de múltiplas modificações no estilo de vida como cessação do tabagismo e consumo alcoólico, a adoção de uma dieta saudável e rica em cálcio, fibra, grãos integrais, frutas, nozes e vegetais bem como a prática regular de atividade física. Estudos mostram que a ingestão de carne processada parece estar envolvida na etiologia do câncer colorretal, cujo risco de desenvolvimento da neoplasia (entre $20 \%$ e 50\% em relação aos não consumidores) está relacionada, entre outros fatores, à temperatura elevada de cozimento, responsável pela formação de aminas heterocíclicas e hidrocarbonetos aromáticos policíclicos com potencial cancerígeno. Além da adoção de um estilo de vida mais saudável, alguns agentes quimiopreventivos podem contribuir para a redução do risco de desenvolvimento desse tumor (Dekker et al., 2019; Marques et al., 2019; Roncucci \& Mariani, 2015; Santarelli et al., 2008).

- Anti-inflamatórios não-esteroidais e inibidores de ciclo-oxigenase-2: o uso prolongado dos AINES tem sido associado à redução dos pólipos adenomatosos e à redução do número de óbitos por câncer colorretal em 30 a 50\% (Tinsley et al., 2013; Tsioulias et al., 2015). A aspirina tem sido um AINE bastante explorado por inibir a síntese de prostaglandina E2 e a atividade das enzimas COX-1, COX-2 e óxido nítrico sintase (NOS); por atuar na modulação da via de sinalização Wnt/ $\beta$ -

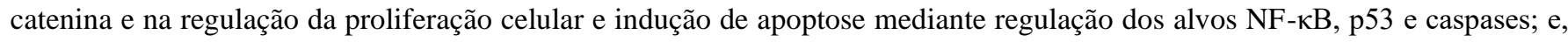
também, por diminuir a expressão de $\beta$-catenina, PCNA e do receptor do tipo Toll 4 (Mohammed et al., 2018). Outro AINE deveras investigado é o celecoxibe. A exposição à dose diária de $400 \mathrm{mg}$ aparenta ser eficaz na prevenção do desenvolvimento de adenomas colorretais em pacientes de alto risco, tal como na sua recorrência, em até 3 anos, após polipectomia. Inobstante, 
qualquer efeito mediado pelo celecoxibe é de curta duração após a retirada desse agente (Arber et al., 2006; Thompson et al., 2016). Esses efeitos são decorrentes da inibição de COX-2 e da via de sinalização Wnt/ $\beta$-catenina e dos respectivos produtos dos seus genes alvos, como survivina e ciclina D1 (Mohammed et al., 2018). Com tais estudos, o FDA concedeu aprovação provisória ao celecoxibe para sua utilização como um adjuvante à vigilância padrão e como profilaxia cirúrgica em indivíduos com polipose adenomatosa familiar (Hawk et al., 2004). Tem sido atestado que AINEs não aspirínicos são os agentes mais eficazes na quimioprevenção de tumores colorretais, apesar de sua baixa classificação no quesito segurança. Já no que diz respeito ao uso da aspirina, apesar de sua eficácia inferior, ainda assim, em baixa dose, é o agente com o perfil risco-benefício mais favorável (Dulai et al., 2016).

- Metformina: um dos principais vínculos entre o câncer colorretal e o diabetes mellitus é a hiperinsulinemia e a resistência à insulina (Kamarudin et al., 2019). Em 1957, foi aprovado pelo FDA o uso da metformina para o tratamento do diabetes mellitus tipo 2. Além de seus efeitos protetores hipoglicemiantes e cardiovasculares, estudos têm evidenciado seu envolvimento em diversos mecanismos celulares que levam a um efeito antitumoral. Um dos mecanismos que demonstra estar associado ao efeito antineoplásico da metformina é a inibição da via PI3K/Akt/mTOR como resultado da redução dos níveis séricos da insulina e do fator de crescimento semelhante à insulina (IGF, "Insulin-like Growth Factor") (Kamarudin et al., 2019; Zi et al., 2018).

Em ratos diabéticos tipo 2, a metformina demonstrou diminuir a formação de focos de criptas aberrantes (FCA) e a proliferação do tecido do cólon, determinado pelo antígeno PCNA. Este efeito parece estar atrelado à regulação da expressão de enzimas envolvidas no metabolismo da glicose e no ciclo de Krebs (Jia et al., 2015). Em células HT-29 e HCT-116, a metformina foi capaz de, sinergicamente em combinação com a oxaliplatina, inibir a migração celular e a formação de colonosferas, bem como de induzir a morte celular. Como decorrência do tratamento combinatório, achados moleculares revelam a inibição da via de sinalização Wnt/ $\beta$-catenina, e a diminuição e o aumento da expressão do miRNA 21 e do miRNA 145 , respectivamente. Dados provenientes do tratamento combinado de oxaliplatina e metformina em modelos de xenoenxerto de camundongos SCID ("Severe combined Immunodeficiency") evidenciam uma inibição de 50\% do crescimento dos tumores após 5 semanas de tratamento (Nangia-Makker et al., 2014).

Sob a perspectiva clínica, um estudo de fase 3, multicêntrico, duplo-cego, controlado por placebo e randomizado, recrutou pacientes adultos não diabéticos designados aleatoriamente para receber $250 \mathrm{mg} / \mathrm{d}$ de metformina oral ou placebo. Os dados demonstraram que a administração em baixa dose por um ano não só reduziu a prevalência e o número de adenomas ou pólipos, como também se mostrou segura e bem tolerável (Higurashi et al., 2016).

- Difluorometilornitina (DFMO): Kingsnorth e colaboradores (1983) demonstraram a atividade antitumoral da DFMO em modelo in vivo de carcinogênese colorretal induzida por 1,2-dimetilhidrazina (Kingsnorth et al., 1983). No entanto, dependendo da dose administrada, sérios efeitos colaterais (anormalidades gastrointestinais, trombocitopenia e ototoxicidade) podem ser ocasionados (Abeloff et al., 1984; Horn et al., 1987; Meyskens et al., 1986). Em 1998, em um ensaio clínico de fase IIb, determinou-se a dose de $0,20 \mathrm{~g} / \mathrm{m}^{2}$ como ideal e segura na inibição da biossíntese de poliaminas da mucosa retal (Meyskens et al., 1998).

Ignatenko e colaboradores (2008) utilizaram camundongos $\mathrm{Apc}^{\mathrm{Min} /+}$ para explorar o papel quimiopreventivo do DFMO. O tratamento com DFMO individualmente foi capaz de suprimir o desenvolvimento dos tumores intestinais em 55\%. A combinação de DFMO com um AINE (celecoxibe ou sulindaco) levou a uma redução em mais de 80\% no número dos tumores (Ignatenko et al., 2008).

Na clínica, a combinação de DFMO com o sulindaco (AINE) reduziu a recorrência de tumores quando administrada pelo período de 36 meses em pacientes com histórico de ressecção de adenomas colorretais ( $\geq 3 \mathrm{~mm}$ ) em 70\%, 92\% e 95\%, em todos os adenomas, em adenomas avançados e em adenomas recorrentes, respectivamente (Meyskens et al., 2008). 
- Ácido ursodesoxicólico (AUDC): o AUDC é um ácido biliar terciário, aprovado pelo FDA e utilizado na prevenção de cálculos na vesícula biliar e no tratamento da cirrose biliar primária (CBP). Apresenta propriedades antioxidantes, antiinflamatórias e citoprotetoras. Em células tumorais do cólon, o AUDC aumenta a expressão dos inibidores p27 e p21 levando à parada do ciclo celular nas fases G1/S e G2/M. Além disso, regula os níveis intracelulares das espécies reativas de oxigênio (ROS) e inibe a formação de células tronco tumorais (Goossens \& Bailly, 2019; Kim et al., 2017). Em ratos, o AUDC inibe COX-2 e suprime o desenvolvimento de tumores em animais que expressam a forma selvagem e mutante de Ras (Khare et al., 2003).

Em um ensaio clínico de fase III, 1.285 indivíduos, com histórico de remoção de adenoma colorretal nos últimos 6 meses anteriores ao início do estudo, foram designados aleatoriamente para o tratamento diário com AUDC (8-10 mg/kg p.c) ou com placebo por 3 anos. Foi encontrada uma redução estatisticamente significativa de 39\% na recorrência de adenomas com displasia de alto grau, um achado promissor dado o elevado risco existente de progressão de uma lesão displásica grave para um carcinoma colorretal invasivo (Alberts et al., 2005). O efeito quimioprotetor baseado na redução de $74 \%$ do risco de displasia foi demonstrado em pacientes com colite ulcerativa (CU) e colangite esclerosante primária (CEP) (Pardi et al., 2003). Um programa de vigilância colonoscópica da Universidade de Washington observou resultados equivalentes: 59 pacientes com CU e CEP demonstraram menor frequência de displasia colônica após uso de AUDC (Tung et al., 2001). Em pacientes com CBP, doses de 13 a $15 \mathrm{mg} / \mathrm{kg} / \mathrm{d}$ de AUDC estão associadas à menor prevalência de adenomas colorretais e à redução da expressão do antígeno Ki67 (Serfaty et al., 2003).

- Estatinas: atorvastatina, cerivastatina, fluvastatina e pravastatina são potentes inibidores da 3-hidroxi-3metilglutaril-coenzima A (HMG-CoA) redutase, enzima chave na conversão da HMG-CoA em ácido mevalônico (Stancu \& Sima, 2001). Estudos demonstram, também, um papel significativo do melavonato no processo de proliferação celular, bem como o aumento da atividade da HMG-CoA redutase em células tumorais, o que torna essa classe de fármacos potenciais agentes quimiopreventivos/quimioterapêuticos (Stancu \& Sima, 2001).

Em uma meta-análise conduzida por Li e colaboradores (2019), envolvendo um total de 14 estudos e 130.994 pacientes, foi demostrado que os usos de estatina pré-diagnóstico e pós-diagnóstico estão associados a uma melhora do quadro geral e da sobrevida em pacientes com câncer colorretal (Li et al., 2019). Esses efeitos se devem, em parte, à capacidade das estatinas de inibir os processos de invasão e metástase, visto que a prevalência de metástases em usuários se mostra $30 \%$ menor. Além disso, já foi demonstrado que o pré-tratamento in vitro com lovastatina potencializa a apoptose induzida por 5fluorouracil e cisplatina em linhagens tumorais de cólon com perfil de resistência, sugerindo o emprego das estatinas também no processo de superação da quimiorresistência das células tumorais (Bardou et al., 2010).

- Mesalazina: fármaco derivado da aspirina, utilizado na terapia de primeira-linha da colite ulcerativa e da Doença de Chron (Bezzio et al., 2017; Sehgal et al., 2018). Similarmente aos AINEs, ela é capaz de atuar em células tumorais colônicas por mecanismos dependentes e independentes de COX, sendo a regulação negativa do eixo COX-2/ prostaglandina E2 um dos meios utilizados. A melasazina inibe o receptor do fator de crescimento epidérmico (EGFR, "Epidermal Growth Factor

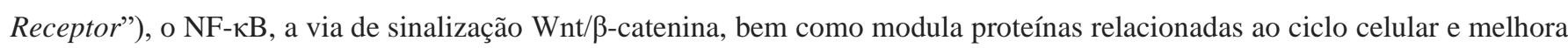
a fidelidade de replicação. Paralelamente, a ativação do receptor gama ativado por proliferador de peroxissoma (PPAR- $\gamma$, "Peroxisome Proliferator-Activated Receptor $\gamma$ "), por este fármaco, desempenha um papel inibidor no crescimento e na proliferação celular, favorecendo a diferenciação (Bezzio et al., 2017; Vella et al., 2017).

São preponderantes os ensaios clínicos com resultados positivos para a avaliação do efeito quimiopreventivo em pacientes com colite ulcerativa. Por outro lado, ainda há dados que contradizem tal efeito. Apesar disso, considerando a cronicidade dos mecanismos inflamatórios como gatilho do processo de carcinogênese, aliado ao perfil de segurança deste fármaco, o uso da mesalazina pode ser fomentada (Bezzio et al., 2017; Herfarth, 2012). 
- Fibra alimentar e Ácidos graxos poli-insaturados de cadeia longa: um dos efeitos benéficos relacionados ao consumo de fibras alimentares é a redução da duração de exposição aos agentes genotóxicos e carcinogênicos, aos quais o epitélio intestinal está constantemente em contato devido a aceleração do trânsito intestinal e ao aumento do volume fecal. Além disso, as fibras têm efeito prebióticos, alterando a expressão de diversos genes nas células tumorais como consequência da produção de ácidos graxos de cadeia curta pós fermentação pela microbiota intestinal (Gianfredi et al., 2019; Liong, 2008). Como resultância desses efeitos, estudos apontam para uma redução de $10 \%$ e $20 \%$ do risco de desenvolvimento do câncer colorretal com a ingestão diária de cada $10 \mathrm{~g}$ de fibra alimentar, e de cada $90 \mathrm{~g}$ (3 porções) de grãos inteiros, respectivamente (Aune et al., 2011).

A ingestão de óleos de peixe e de vegetais, também está associada a uma diminuição do risco de desenvolvimento e morte não só do câncer colorretal, mas outros tumores, como mama e próstata (Lenihan-Geels et al., 2016). Seus benefícios são atribuídos, especialmente, ao alto teor dos ácidos graxos poliinsaturados ômega-3 (n-3 PUFAs, "Omega-3 polyunsaturated fatty acids") docosahexaenóico e eicosapentaenóico (Lee et al., 2017). Alguns dos principais mecanismos quimiopreventivos dos n-3 PUFAs estão vinculados à inibição do crescimento e à indução de apoptose das células tumorais pela modulação de vias como MAPK/Erk, Wnt// $\beta$-catenina e PI3K-PTEN, bem como pela modulação de vias inflamatórias e inibição da síntese de COX-2 e de eicosanóides, além do aumento de peroxidação lipídica e estresse oxidativo intracelular (Volpato \& Hull, 2018; Yurko-Mauro et al., 2020).

A ingestão total de peixes e crustáceos se mostra inversamente associada ao risco de câncer colorretal, de modo que a ingestão semanal de 100 a 200 g acarreta em uma redução de 7\% no risco de desenvolvimento da neoplasia (Aglago et al., 2020). Ao se comparar o perfil bioquímico de pacientes oncológicos com pacientes saudáveis, nota-se que os níveis séricos de PUFAs, em pacientes com câncer colorretal, são significativamente mais baixos. Estudos comparativos in vitro de células incubadas com PUFAs, por 72 horas, revelaram concentrações significativamente mais baixas nos meios de cultura das células transformadas de cólon (HT-29 e WiDr) do que nas células controle normais (CCD $841 \mathrm{CoN}$ ). Este fenômeno se mostrou ser decorrente da absorção preferencial de PUFAs pelas células cancerosas. À vista disso, os dados obtidos questionam os benefícios potenciais da suplementação de PUFA em pacientes com câncer colorretal, uma vez que sugerem que essas moléculas, ao serem absorvidas, possam atuar como substrato chave para a síntese de fosfolipídeos da membrana celular, promovendo a proliferação mais rápida dessas células tumorais (Mika et al., 2020).

- Cálcio e vitamina D: a vitamina D é classicamente conhecida por seu papel fisiológico na regulação do transporte de cálcio e fósforo e na mineralização óssea, assim, muitos dos efeitos da vitamina D são dependentes ou vinculados ao cálcio. No entanto, sua interação com o receptor de vitamina D (VDR, "Vitamin D Receptor") traz à tona funções na regulação de processos patogênicos através da regulação da expressão de genes relacionados à tumorigênese ou da mediação de proliferação celular, adesão, migração, metástase e angiogênese, dentre outros (Tagliabue et al., 2015).

O VDR é membro da superfamília de receptores nucleares de hormônios esteroides, e, como tal, atua como um fator de transcrição ativado por ligante, no caso o 1,25-dihidroxivitamina D3 (1,25(OH)2D3) - a forma biologicamente ativa da vitamina D (Bikle, 2014). Numerosas vias são reguladas pela 1,25(OH)2D3. Efeitos antiproliferativos são decorrentes da redução de ciclinas e de genes como MYC, FOS e JUN. A inibição dos fatores IGF e EGFR e o aumento de inibidores de CDKs, como p21 e p27, também são relatados. Ainda, o complexo 1,25(OH)2D3-VDR compete com a $\beta$-catenina por seus sítios de ligação e inibe a ativação da via Wnt/ $\beta$-catenina. Efeitos de promoção de apoptose, supressão de prostaglandinas, redução da resposta angiogênica e inibição das capacidades invasiva e migratória das células tumorais se somam para o potencial quimiopreventivo da vitamina D (Bikle, 2014). Dados de estudos observacionais apoiam a hipótese de que uma maior ingestão de vitamina D e cálcio reduzem a incidência de câncer colorretal. Um estudo de cohort realizado com 136.249 participantes observou que a ingestão de cálcio acima de $1200 \mathrm{mg} /$ dia se associava inversamente com a incidência de câncer 
colorretal (Yang et al., 2019). Nesse sentido, 4 meta-análises publicadas em 2011 concluíram que níveis séricos ou plasmáticos mais elevados de 1,25(OH)2D3 são associados ao menor risco de câncer colorretal (Mondul et al., 2017). Ainda, diversos autores relatam a associação entre a suplementação com vitamina $\mathrm{D}$ e a maior taxa de sobrevivência e menor recorrência em pacientes com câncer colorretal (Fuchs et al., 2017; Ng et al., 2008). No entanto, particularmente para a vitamina D, estudos recentes não comprovam estatisticamente a relação de tal suplementação com a redução da incidência do câncer (Brown, 2019; Joanna et al., 2019), o que pode ser devido às limitações de amostragem, com vieses demográficos e de número de participantes, além da influência do status de expressão dos receptores VDR e CASR (Al-Ghafari et al., 2019; Brown, 2019; Vaughan-Shaw et al., 2017; Yan et al., 2019; Yang et al., 2019).

- Probióticos: a modificação da microbiota intestinal é sugerida como o primeiro potencial mecanismo de ação anticarcinogênica dos probióticos, uma vez que evita a ocorrência de disbiose e reduz a inflamação crônica e a produção de compostos citotóxicos e genotóxicos a partir da metabolização de componentes da dieta. Ainda, é hipotetizada a neutralização ou degradação de tais substâncias nocivas presentes no lúmen intestinal por parte de bactérias probióticas, através da troca iônica com os peptidoglicanos de sua parede celular (dos Reis et al., 2017a; Tiptiri-Kourpeti et al., 2016).

Produtos finais da fermentação bacteriana de carboidratos, como o butirato, acetato e o propionato são capazes de aumentar a produção de muco e a proliferação de colonócitos, auxiliando na manutenção da barreira intestinal. Além disso, são capazes de reduzir as citocinas inflamatórias a partir da inibição do NF-kB, regular proteínas pró- e anti-apoptóticas, e elevar a atividade antioxidante da enzima glutationa S-transferase (GST), dentre outros (dos Reis et al., 2017b; Eslami et al., 2019). A modulação da proliferação celular e a apoptose foi demonstrada em decorrência da inibição do gene anti-apoptótico $B C L-2$ e do aumento da expressão do pró-apoptótico $B A X$ (dos Reis et al., 2017b; Sharaf et al., 2018).

Dessa maneira, são progressivamente angariadas evidências que suportam o efeito benéfico de probióticos sobre a carcinogênese. Uma revisão sistemática com 34 estudos indicou que 86,6\% das investigações no tema encontraram uma redução significativa de lesões pré-neoplásicas e tumores em animais que receberam probióticos, dentre os quais se destacam espécies dos gêneros Lactobacillus e Bifidobacterium (Brasiel et al., 2020). Em humanos, a aplicação de probióticos antes e após cirurgia reduz bactérias patogênicas e complicações pós-operatórias, recria a integridade da mucosa intestinal, estimula o sistema imune e previne a ocorrência de metástase no câncer colorretal (Eslami et al., 2019).

\section{Conclusão}

O câncer é uma patologia de múltiplos elementos etiológicos, cujo desenvolvimento vincula-se à predisposição genética e a fatores carcinogênicos externos provenientes da dieta e do estilo de vida. Grandes desafios se apresentam desde o diagnóstico até o tratamento, fazendo-se necessários constantes esforços para o progresso das ferramentas clínicas. O conceito de quimioprevenção é intuitivamente instigante, pois implica evitar o sofrimento causado pelo câncer, tendo potencial efeito desde o diagnóstico, no prognóstico e, também, no tratamento. Frente a novos agentes quimioterápicos cada vez mais dispendiosos e, ainda assim, com eficácia limitada, se faz necessária uma maior abertura a uma abordagem alternativa para o tratamento do câncer, e a quimioprevenção apresenta-se como uma estratégia promissora perante os diversos impasses impostos pelos tratamentos atuais. Nada obstante, ainda que notáveis os resultados obtidos por diversos estudos in vitro e in vivo, tal qual as histórias de sucesso clínico, os desafios ainda são muitos, devido às variáveis encontradas nas respostas individuais dos pacientes, as quais podem ser influenciadas pela interação com outros compostos, heterogeneidade genética, especificidades do quadro clínico, entre outros fatores, como também as limitações de investimento e adesão. Isso posto, é importante que se invista em programas educacionais e campanhas de conscientização do público em geral e de profissionais da saúde a respeito dos benefícios por trás da quimioprevenção do câncer. Além disso, a contribuição que pode ser mediada por grandes organizações mundiais apresenta um papel importante no fortalecimento das relações de saúde. 
Apesar de tais dificuldades, os efeitos relatados pelos estudos elencados nessa revisão e as vantagens do uso de quimiopreventivos representam grandes contribuições e potencialidades. Logo, tendo em vista as variações de respostas aos agentes quimiopreventivos em decorrência da variabilidade genética, novos estudos devem ser fomentados com o objetivo de tornar a abordagem preventiva mais personalizada.

\section{Referências}

Abeloff, M. D., Slavik, M., Luk, G. D., Griffin, C. A., Hermann, J., Blanc, O., Sjoerdsma, A., \& Baylin, S. B. (1984). Phase I trial and pharmacokinetic studies of $\alpha$-difluoromethylornithine - An inhibitor of polyamine biosynthesis. Journal of Clinical Oncology, 2(2), 124-130. https://doi.org/10.1200/JCO.1984.2.2.124

Aglago, E. K., Huybrechts, I., Murphy, N., Casagrande, C., Nicolas, G., Pischon, T., Fedirko, V., Severi, G., Boutron-Ruault, M. C., Fournier, A., Katzke, V., Kühn, T., Olsen, A., Tjønneland, A., Dahm, C. C., Overvad, K., Lasheras, C., Agudo, A., Sánchez, M. J., ... Gunter, M. J. (2020). Consumption of Fish and Long-chain n-3 Polyunsaturated Fatty Acids Is Associated With Reduced Risk of Colorectal Cancer in a Large European Cohort. Clinical Gastroenterology and Hepatology, 18(3), 654-666.e6. https://doi.org/10.1016/j.cgh.2019.06.031

Ahn, J. H., Lee, K. T., Choi, Y. S., \& Choi, J. H. (2018). Iloprost, a prostacyclin analog, inhibits the invasion of ovarian cancer cells by downregulating matrix metallopeptidase-2 (MMP-2) through the IP-dependent pathway. Prostaglandins and Other Lipid Mediators, 134, 47-56. https://doi.org/10.1016/j.prostaglandins.2017.12.002

Al-Ghafari, A. B., Balamash, K. S., \& Al Doghaither, H. A. (2019). Relationship between Serum Vitamin D and calcium levels and Vitamin D receptor gene polymorphisms in colorectal cancer. BioMed Research International, 2019. https://doi.org/10.1155/2019/8571541

Alberts, D. S., Martínez, M. E., Hess, L. M., Einspahr, J. G., Green, S. B., Bhattacharyya, A. K., Guillen, J., Krutzsch, M., Batta, A. K., Salen, G., Fales, L., Koonce, K., Parish, D., Clouser, M., Roe, D., \& Lance, P. (2005). Phase III trial of ursodeoxycholic acid to prevent colorectal adenoma recurrence. Journal of the National Cancer Institute, 97(11), 846-853. https://doi.org/10.1093/jnci/dji144

Alexiou, G. A., Lianos, G. D., Ragos, V., Galani, V., \& Kyritsis, A. P. (2017). Difluoromethylornithine in cancer: New advances. Future Oncology, 13(9). https://doi.org/10.2217/fon-2016-0266

Amararathna, M., Johnston, M. R., \& Rupasinghe, H. P. V. (2016). Molecular Sciences Plant Polyphenols as Chemopreventive Agents for Lung Cancer. https://doi.org/10.3390/ijms17081352

Amorim, M. O., Vieira, M. M., Gonçalves, I. V., Rhana, P., \& Rodrigues, A. L. P. (2018). Breast Cancer: tumoral metabolism reprogramming. Revista Médica de Minas Gerais, 28. https://doi.org/10.5935/2238-3182.20180078

Andrade, S., \& Andrade, S. A. F. de. (2014). Câncer de mama: um problema de saúde pública. UNILUS Ensino e Pesquisa, 11(23), 70-77. http://revista.lusiada.br/index.php/ruep/article/view/169

Araghi, S. O., Kiefte-De Jong, J. C., Van Dijk, S. C., Swart, K. M. A., Van Laarhoven, H. W., Van Schoor, N. M., De Groot, L. C. P. G. M., Lemmens, V., Stricker, B. H., Uitterlinden, A. G., \& Van Der Velde, N. (2019). Folic acid and Vitamin B12 supplementation and the risk of cancer: Long-term Follow-up of the B Vitamins for the Prevention of Osteoporotic Fractures (B-PROOF) Trial. Cancer Epidemiology Biomarkers and Prevention, 28(2), 275-282. https://doi.org/10.1158/1055-9965.EPI-17-1198

Araújo, L. R. L. de, Viana, F. C. V., Casimiro, V. C., Nogueira, T. B. de S. de S., \& Sousa, M. N. A. de. (2016). Antioxidantes na prevenção do câncer em idosos. Journal of Medicine and Health Promotion, 1(1), 18-26.

Araujo, L. H., Baldotto, C., De Castro, G., Katz, A., Ferreira, C. G., Mathias, C., Mascarenhas, E., Lopes, G. de L., Carvalho, H., Tabacof, J., Martínez-Mesa, J., Viana, L. de S., Cruz, M. de S., Zukin, M., De Marchi, P., Terra, R. M., Ribeiro, R. A., De Lima, V. C. C., Werutsky, G., \& Barrios, C. H. (2018). Câncer de pulmão no Brasil. Jornal Brasileiro de Pneumologia, 44(1), 55-64. https://doi.org/10.1590/s1806-37562017000000135

Arber, N., Eagle, C. J., Spicak, J., Rácz, I., Dite, P., Hajer, J., Zavoral, M., Lechuga, M. J., Gerletti, P., Tang, J., Rosenstein, R. B., Macdonald, K., Bhadra, P., Fowler, R., Wittes, J., Zauber, A. G., Solomon, S. D., \& Levin, B. (2006). Celecoxib for the Prevention of Colorectal Adenomatous Polyps. New England Journal of Medicine, 355(9), 885-895. https://doi.org/10.1056/nejmoa061652

Arisan, E. D., Ergül, Z., Bozdağ, G., Rencüzoğulları, Ö., Çoker-Gürkan, A., Obakan-Yerlikaya, P., Coşkun, D., \& Palavan-Ünsal, N. (2018). Diclofenac induced apoptosis via altering PI3K/Akt/MAPK signaling axis in HCT 116 more efficiently compared to SW480 colon cancer cells. Molecular Biology Reports, 45(6), 2175-2184. https://doi.org/10.1007/s11033-018-4378-2

Arumugam, A., \& Razis, A. F. A. (2018). Apoptosis as a mechanism of the cancer chemopreventive activity of glucosinolates: A review. In Asian Pacific Journal of Cancer Prevention (Vol. 19, Issue 6, pp. 1439-1448). Asian Pacific Organization for Cancer Prevention. https://doi.org/10.22034/APJCP.2018.19.6.1439

Ataollahi, M. R., Sharifi, J., Paknahad, M. R., \& Paknahad, A. (2015). Breast cancer and associated factors: a review. Journal of Medicine and Life, 8(Spec Iss 4), 6-11. http://www.ncbi.nlm.nih.gov/pubmed/28316699

Aune, D., Chan, D. S. M., Lau, R., Vieira, R., Greenwood, D. C., Kampman, E., \& Norat, T. (2011). Dietary fibre, whole grains, and risk of colorectal cancer: Systematic review and dose-response meta-analysis of prospective studies. In BMJ (Online) (Vol. 343, Issue 7833, p. 1082). BMJ. https://doi.org/10.1136/bmj.d6617

Ball, S., Arevalo, M., Juarez, E., Payne, J. D., \& Jones, C. (2019). Breast cancer chemoprevention: An update on current practice and opportunities for primary care physicians. Preventive Medicine, 129. https://doi.org/10.1016/j.ypmed.2019.105834 
Barbalata, C. I., Tefas, L. R., Achim, M., Tomuta, I., \& Porfire, A. S. (2020). Statins in risk-reduction and treatment of cancer. World Journal of Clinical Oncology, 11(8), 573-588. https://doi.org/10.5306/wjco.v11.i8.573

Barchiesi, G., Mazzotta, M., Krasniqi, E., Pizzuti, L., Marinelli, D., Capomolla, E., Sergi, D., Amodio, A., Natoli, C., Gamucci, T., Vizza, E., Marchetti, P., Botti, C., Sanguineti, G., Ciliberto, G., Barba, M., \& Vici, P. (2020). Neoadjuvant endocrine therapy in breast cancer: Current knowledge and future perspectives. International Journal of Molecular Sciences, 21(10), 3528. https://doi.org/10.3390/ijms21103528

Bardou, M., Barkun, A., \& Martel, M. (2010). Effect of statin therapy on colorectal cancer. Gut, 59(11), 1572-1585. https://doi.org/10.1136/gut.2009.190900

Bauman, J. E., Zang, Y., Sen, M., Li, C., Wang, L., Egner, P. A., Fahey, J. W., Normolle, D. P., Grandis, J. R., Kensler, T. W., \& Johnson, D. E. (2016). Prevention of carcinogen-induced oral cancer by sulforaphane. Cancer Prevention Research, 9(7), 547-557. https://doi.org/10.1158/1940-6207.CAPR-150290

Benetou, V., Lagiou, A., \& Lagiou, P. (2015). Chemoprevention of cancer: Current evidence and future prospects. F1000Research, 4, 1-10. https://doi.org/10.12688/f1000research.6684.1

Bezzio, C., Festa, S., Saibeni, S., \& Papi, C. (2017). Chemoprevention of colorectal cancer in ulcerative colitis: digging deep in current evidence. Expert Review of Gastroenterology and Hepatology, 11(4), 339-347. https://doi.org/10.1080/17474124.2017.1292129

Bikle, D. D. (2014). Vitamin D and cancer: The promise not yet fulfilled. Endocrine, 46(1), 29-38. https://doi.org/10.1007/s12020-013-0146-1

Borsatto, A. Z., Vidal, M. L. B., \& Rocha, R. C. N. P. (2011). Vacina contra o HPV e a Prevenção do Câncer do Colo do Útero: Subsídios para a Prática. Revista Brasileira de Cancerologia, 57(1), 67-74. https://doi.org/10.32635/2176-9745.rbc.2011v57n1.690

Brasiel, P. G. de A., Dutra Luquetti, S. C. P., Peluzio, M. do C. G., Novaes, R. D., \& Gonçalves, R. V. (2020). Preclinical Evidence of Probiotics in Colorectal Carcinogenesis: A Systematic Review. Digestive Diseases and Sciences, 0123456789. https://doi.org/10.1007/s10620-020-06062-3

Brasky, T. M., Lampe, J. W., Potter, J. D., Patterson, R. E., \& White, E. (2010). Specialty supplements and breast cancer risk in the VITamins and Lifestyle (VITAL) cohort. Cancer Epidemiology Biomarkers and Prevention, 19(7), 1696-1708. https://doi.org/10.1158/1055-9965.EPI-10-0318

Brown, R. B. (2019). Vitamin D, cancer, and dysregulated phosphate metabolism. Endocrine, 65(2), 238-243. https://doi.org/10.1007/s12020-019-01985-y

Bujanda, L., Rodríguez-González, A., Sarasqueta, C., Eizaguirre, E., Hijona, E., Marín, J. J. G., Perugorria, M. J., Banales, J. M., \& Cosme, A. (2016). Effect of pravastatin on the survival of patients with advanced gastric cancer. Oncotarget, 7(4), 4379-4384. https://doi.org/10.18632/oncotarget.6777

Butler, G. J., Neale, R., Green, A. C., Pandeya, N., \& Whiteman, D. C. (2005). Nonsteroidal anti-inflammatory drugs and the risk of actinic keratoses and squamous cell cancers of the skin. Journal of the American Academy of Dermatology, 53(6), 966-972. https://doi.org/10.1016/j.jaad.2005.05.049

Cai, X., Wang, C., Yu, W., Fan, W., Wang, S., Shen, N., Wu, P., Li, X., \& Wang, F. (2016). Selenium Exposure and Cancer Risk: An Updated Meta-analysis and Meta-regression. Scientific Reports, 6. https://doi.org/10.1038/srep19213

Cajueiro, E. de S., Bringel, L., Lima, R., \& Partata, A. K. (2014). Isotretinoína e suas propriedades farmacológicas. Revista ITPAC, 7(1).

Camp, W. L., Turnham, J. W., Athar, M., \& Elmets, C. A. (2011). New Agents for Prevention of Ultraviolet-Induced Nonmelanoma Skin Cancer. Seminars in Cutaneous Medicine and Surgery, 30(1), 6-13. https://doi.org/10.1016/j.sder.2011.01.003

Carbone, P. P., Pirsch, J. D., Thomas, J. P., Douglas, J. A., Verma, A. K., Larson, P. O., Snow, S., Tutsch, K. D., \& Pauk, D. (2001). Phase I Chemoprevention Study of Difluoromethylornithine in Subjects with Organ Transplants. Cancer Epidemiology and Prevention Biomarkers, 10(6).

Chen, A. C., Halliday, G. M., \& Damian, D. L. (2013). Non-melanoma skin cancer: Carcinogenesis and chemoprevention. Pathology, 45(3), 331-341. https://doi.org/10.1097/PAT.0b013e32835f515c

Chen, B., Zhang, M., Xing, D., \& Feng, Y. (2017). Atorvastatin enhances radiosensitivity in hypoxia-induced prostate cancer cells related with HIF-1a inhibition. Bioscience Reports, 37(4), 20170340. https://doi.org/10.1042/BSR20170340

Collery, P. (2018). Strategies for the development of selenium-based anticancer drugs. Journal of Trace Elements in Medicine and Biology, 50, 498-507. https://doi.org/10.1016/j.jtemb.2018.02.024

Cummings, S. R., McClung, M., Reginster, J. Y., Cox, D., Mitlak, B., Stock, J., Amewou-Atisso, M., Powles, T., Miller, P., Zanchetta, J., \& Christiansen, C. (2011). Arzoxifene for prevention of fractures and invasive breast cancer in postmenopausal women. Journal of Bone and Mineral Research, 26(2), 397-404. https://doi.org/10.1002/jbmr.191

Curran, M. P., \& Goa, K. L. (2003). Lovastatin Extended Release. Drugs, 63(7), 685-699. https://doi.org/10.2165/00003495-200363070-00007

Cuzick, J., Sestak, I., Forbes, J. F., Dowsett, M., Cawthorn, S., Mansel, R. E., Loibl, S., Bonanni, B., Evans, D. G., \& Howell, A. (2020). Use of anastrozole for breast cancer prevention (IBIS-II): long-term results of a randomised controlled trial. The Lancet, 395(10218), 117-122. https://doi.org/10.1016/S01406736(19)32955-1

D’Orazio, J., Jarrett, S., Amaro-Ortiz, A., \& Scott, T. (2013). UV radiation and the skin. International Journal of Molecular Sciences, 14(6), $12222-12248$. https://doi.org/10.3390/ijms140612222

Damiani, E., \& Wallace, H. M. (2018). Polyamines and cancer. Methods in Molecular Biology, 1694, 469-488. https://doi.org/10.1007/978-1-4939-7398-9_39

Das, B. C., Thapa, P., Karki, R., Das, S., Liu, T., Torregroza, I., Wallace, D. P., Veldhuizen, P. Van, Verma, A., Ray, S. K., Evans, T., City, K., Medical, V. A., City, K., \& City, K. (2014). Retinoic Acid Signaling Pathways in Development and Diseases Bhaskar. Bioorg Med Chem, 22(2), 673-683. https://doi.org/10.1016/j.bmc.2013.11.025.Retinoic 
De Flora, S., \& Ferguson, L. R. (2005). Overview of mechanisms of cancer chemopreventive agents. Mutation Research - Fundamental and Molecular Mechanisms of Mutagenesis, 591(1-2), 8-15. https://doi.org/10.1016/j.mrfmmm.2005.02.029

De Oliveira, V. M., \& Aldrighi, J. M. (2006). New pharmacological alternative in breast cancer prevention after menopause. Revista Da Associacao Medica Brasileira, 52(4), 192-193. https://doi.org/10.1590/s0104-42302006000400006

Dekker, E., Tanis, P. J., Vleugels, J. L. A., Kasi, P. M., \& Wallace, M. B. (2019). Colorectal cancer. The Lancet, 394(10207), 1467-1480. https://doi.org/10.1016/S0140-6736(19)32319-0

Denipote, F. G., Trindade, E. B. S. D. M., \& Burini, R. C. (2010). Probióticos e prebióticos na atenção primária ao câncer de cólon. In Arquivos de Gastroenterologia (Vol. 47, Issue 1, pp. 93-98). Instituto Brasileiro de Estudos e Pesquisas de Gastroenterologia e Outras Especialidades - IBEPEGE. https://doi.org/10.1590/S0004-28032010000100016

Di Bello, E., Zwergel, C., Mai, A., \& Valente, S. (2020). The Innovative Potential of Statins in Cancer: New Targets for New Therapies. Frontiers in Chemistry, 8(June), 1-9. https://doi.org/10.3389/fchem.2020.00516

dos Reis, S. A., da Conceição, L. L., Siqueira, N. P., Rosa, D. D., da Silva, L. L., \& Peluzio, M. do C. G. (2017a). Review of the mechanisms of probiotic actions in the prevention of colorectal cancer.pdf. Nutrition Research, 1(19).

dos Reis, S. A., da Conceição, L. L., Siqueira, N. P., Rosa, D. D., da Silva, L. L., \& Peluzio, M. do C. G. (2017b). Review of the mechanisms of probiotic actions in the prevention of colorectal cancer. Nutrition Research, 37, 1-19. https://doi.org/10.1016/j.nutres.2016.11.009

Dubas, L. E., \& Ingraffea, A. (2013). Nonmelanoma Skin Cancer. Facial Plastic Surgery Clinics of North America, 21(1), 43-53. https://doi.org/10.1016/j.fsc.2012.10.003

Dulai, P. S., Singh, S., Marquez, E., Khera, R., Prokop, L. J., Limburg, P. J., Gupta, S., \& Murad, M. H. (2016). Chemoprevention of colorectal cancer in individuals with previous colorectal neoplasia: Systematic review and network meta-analysis. BMJ (Online), 355. https://doi.org/10.1136/bmj.i6188

Einspahr, J. G., Nelson, M. A., Saboda, K., Warneke, J., Bowden, G. T., \& Alberts, D. S. (2002). Modulation of Biologic Endpoints by Topical Difluoromethylornithine (DFMO), in Subjects at High-Risk for Nonmelanoma Skin Cancer. Clinical Cancer Research, 8(1).

El-Bayoumy, K., Rose, D. P., Papanikolaou, N., Leszczynska, J., Swamy, M. V., \& Rao, C. V. (2002). Cyclooxygenase-2 expression influences the growth of human large and small cell lung carcinoma lines in athymic mice: impact of an organoselenium compound on growth regulation. International Journal of Oncology, 20(3), 557-561. https://doi.org/10.3892/ijo.20.3.557

Eslami, M., Yousefi, B., Kokhaei, P., Hemati, M., Nejad, Z. R., Arabkari, V., \& Namdar, A. (2019). Importance of probiotics in the prevention and treatment of colorectal cancer. Journal of Cellular Physiology, 234(10), 17127-17143. https://doi.org/10.1002/jcp.28473

Estatísticas de Câncer. (2021). Instituto Nacional de Câncer. https://www.inca.gov.br/numeros-de-cancer

Fabian, C. J., Kimler, B. F., \& Hursting, S. D. (2015). Omega-3 fatty acids for breast cancer prevention and survivorship. In Breast Cancer Research (Vol. 17, Issue 1, pp. 1-11). BioMed Central Ltd. https://doi.org/10.1186/s13058-015-0571-6

Fernandes, A. P., \& Gandin, V. (2015). Selenium compounds as therapeutic agents in cancer. Biochimica et Biophysica Acta - General Subjects, 1850(8), 1642-1660. https://doi.org/10.1016/j.bbagen.2014.10.008

Fischer, S. M., Lee, M., \& Lubet, R. A. (2001). Difluoromethylornithine is effective as both a preventive and therapeutic agent against the development of UV carcinogenesis in SKH hairless mice. Carcinogenesis, 22(1), 83-88. https://doi.org/10.1093/carcin/22.1.83

Fisher, B., Costantino, J. P., Wickerham, D. L., Redmond, C. K., Kavanah, M., Cronin, W. M., Vogel, V., Robidoux, A., Dimitrov, N., Atkins, J., Daly, M., Wieand, S., Tan-Chiu, E., Ford, L., \& Wolmark, N. (1998). Tamoxifen for prevention of breast cancer: Report of the National Surgical Adjuvant Breast and Bowel Project P-1 study. Journal of the National Cancer Institute, 90(18), 1371-1388. https://doi.org/10.1093/jnci/90.18.1371

Freitas, R. D. S., \& Campos, M. M. (2019). Protective effects of omega-3 fatty acids in cancer-related complications. In Nutrients (Vol. 11, Issue 5). MDPI AG. https://doi.org/10.3390/nu11050945

Fuchs, M. A., Yuan, C., Sato, K., Niedzwiecki, D., Ye, X., Saltz, L. B., Mayer, R. J., Mowat, R. B., Whittom, R., Hantel, A., Benson, A., Atienza, D., Messino, M., Kindler, H., Venook, A., Innocenti, F., Warren, R. S., Bertagnolli, M. M., Ogino, S., ... Ng, K. (2017). Predicted vitamin D status and colon cancer recurrence and mortality in CALGB 89803 (Alliance). Annals of Oncology, 28(6), 1359-1367. https://doi.org/10.1093/annonc/mdx109

Fujiki, H., Watanabe, T., Sueoka, E., Rawangkan, A., \& Suganuma, M. (2018). Cancer prevention with green tea and its principal constituent, EGCG: From early investigations to current focus on human cancer stem cells. Molecules and Cells, 41(2), 73-82. https://doi.org/10.14348/molcells.2018.2227

Galdino, F. M. P. (2017). Efeitos dos fruto-oligossacarídeos (Fos) no pré-tratamento e tratamento sobre a mucosite intestinal, induzida por 5-fluorouracil, em modelo experimental.

Geng, A., Weinstock, M. A., Hall, R., Eilers, D., Naylor, M., \& Kalivas, J. (2009). Tolerability of high-dose topical tretinoin: The Veterans Affairs Topical Tretinoin Chemoprevention Trial. British Journal of Dermatology, 161(4), 918-924. https://doi.org/10.1111/j.1365-2133.2009.09341.x

Gensler, H. L., Timmermann, B. N., Valcic, S., Wächter, G. A., Dorr, R., Dvorakova, K., \& Alberts, D. S. (1996). Prevention of photocarcinogenesis by topical administration of pure epigallocatechin gallate isolated from green tea. Nutrition and Cancer, 26(3), 325-335. https://doi.org/10.1080/01635589609514488

George, R., Weightman, W., Russ, G. R., Bannister, K. M., \& Mathew, T. H. (2002). Acitretin for chemoprevention of non-melanoma skin cancers in renal transplant recipients. Australasian Journal of Dermatology, 43(4), 269-273. https://doi.org/10.1046/j.1440-0960.2002.00613.x

Gianfredi, V., Nucci, D., Salvatori, T., Dallagiacoma, G., Fatigoni, C., Moretti, M., \& Realdon, S. (2019). Rectal cancer: 20\% risk reduction thanks to dietary 
fibre intake. systematic review and meta-analysis. Nutrients, 11(7). https://doi.org/10.3390/nu11071579

Goldstein, S. R., Duvernoy, C. S., Calaf, J., Adachi, J. D., Mershon, J. L., Dowsett, S. A., Agnusdei, D., \& Stuenkel, C. A. (2009). Raloxifene use in clinical practice: Efficacy and safety. Menopause, 16(2), 413-421. https://doi.org/10.1097/gme.0b013e3181883dae

Gomes, F. D. S. (2007). Carotenoids: A possible protection against cancer development. In Revista de Nutricao (Vol. 20, Issue 5, pp. 537-548). Revista de Nutricao. https://doi.org/10.1590/s1415-52732007000500009

Gong, X., Smith, J. R., Swanson, H. M., \& Rubin, L. P. (2018). Carotenoid lutein selectively inhibits breast cancer cell growth and potentiates the effect of chemotherapeutic agents through ROS-mediated mechanisms. Molecules, 23(4). https://doi.org/10.3390/molecules23040905

Goossens, J. F., \& Bailly, C. (2019). Ursodeoxycholic acid and cancer: From chemoprevention to chemotherapy. Pharmacology and Therapeutics, 203. https://doi.org/10.1016/j.pharmthera.2019.107396

Greenberg, A. K., Tsay, J. C., Tchou-Wong, K. M., Jorgensen, A., \& Rom, W. N. (2013). Chemoprevention of lung cancer: Prospects and disappointments in human clinical trials. Cancers, 5(1), 131-148. https://doi.org/10.3390/cancers5010131

Gumushan Aktas, H., \& Akgun, T. (2018). Naringenin inhibits prostate cancer metastasis by blocking voltage-gated sodium channels. Biomedicine and Pharmacotherapy, 106, 770-775. https://doi.org/10.1016/j.biopha.2018.07.008

Gunning, W. T., Kramer, P. M., Steele, V. E., \& Pereira, M. A. (2002). Chemoprevention by Lipoxygenase and Leukotriene Pathway Inhibitors of Vinyl Carbamate-induced Lung Tumors in Mice. Cancer Research, 62(15).

Gwyn, K., \& Sinicrope, F. A. (2002). Chemoprevention of colorectal cancer. American Journal of Gastroenterology, 97(1), 13-21. https://doi.org/10.1016/S0002-9270(01)03997-1

Half, E., \& Arber, N. (2009). Colon cancer: Preventive agents and the present status of chemoprevention. In Expert Opinion on Pharmacotherapy (Vol. 10, Issue 2, pp. 211-219). Expert Opin Pharmacother. https://doi.org/10.1517/14656560802560153

Hardin, J., \& Mydlarski, P. R. (2010). Systemic Retinoids: Chemoprevention of Skin Cancer in Transplant Recipients. Skin Therapy Letter, 15(7). https://www.skintherapyletter.com/skin-cancer/chemoprevention-transplant-recipients/

Hawk, E. T., Umar, A., \& Viner, J. L. (2004). Colorectal Cancer Chemoprevention - An Overview of the Science. Gastroenterology, 126(5), 1423-1447. https://doi.org/10.1053/j.gastro.2004.03.002

Herfarth, H. (2012). The role of chemoprevention of colorectal cancer with 5-aminosalicylates in ulcerative colitis. Digestive Diseases, 30(SUPPL.2), 55-59. https://doi.org/10.1159/000341894

Higurashi, T., Hosono, K., Takahashi, H., Komiya, Y., Umezawa, S., Sakai, E., Uchiyama, T., Taniguchi, L., Hata, Y., Uchiyama, S., Hattori, A., Nagase, H., Kessoku, T., Arimoto, J., Matsuhashi, N., Inayama, Y., Yamanaka, S., Taguri, M., \& Nakajima, A. (2016). Metformin for chemoprevention of metachronous colorectal adenoma or polyps in post-polypectomy patients without diabetes: a multicentre double-blind, placebo-controlled, randomised phase 3 trial. The Lancet Oncology, 17(4), 475-483. https://doi.org/10.1016/S1470-2045(15)00565-3

Horn, Y., Schechter, P. J., \& Marton, L. J. (1987). Phase I-II clinical trial with alpha-difluoromethylornithine-An inhibitor of polyamine biosynthesis. European Journal of Cancer and Clinical Oncology, 23(8), 1103-1107. https://doi.org/10.1016/0277-5379(87)90141-6

Hu, P. J., Wu, M. Y., Lin, T. C., Chen, T. T., Wu, Y. C., Su, S. L., Lu, K. C., Chen, J. S., Sung, F. C., Lee, C. Te, Yang, Y., Hwang, S. J., Wang, M. C., Hsu, Y. H., Chiou, H. Y., Wong, C. S., \& Lin, Y. F. (2018). Effect of Statins on Renal Function in Chronic Kidney Disease Patients. Scientific Reports, 8(1), 1-7. https://doi.org/10.1038/s41598-018-34632-Z

Hussein, M. R. (2005). Ultraviolet radiation and skin cancer: Molecular mechanisms. Journal of Cutaneous Pathology, 32(3), 191-205. https://doi.org/10.1111/j.0303-6987.2005.00281.x

Ianhez, M., Fleury, L. F. F., Miot, H. A., \& Bagatin, E. (2013). Retinoides para a prevenção e tratamento das queratoses actínicas. Anais Brasileiros de Dermatologia, 88(4), 585-593. https://doi.org/10.1590/abd1806-4841.20131803

Ianhez, M., Pinto, S. A., Miot, H. A., \& Bagatin, E. (2019). A randomized, open, controlled trial of tretinoin $0.05 \%$ cream vs. low-dose oral isotretinoin for the treatment of field cancerization. International Journal of Dermatology, 58(3), 365-373. https://doi.org/10.1111/ijd.14363

Ignatenko, N. A., Besselsen, D. G., Stringer, D. E., Blohm-Mangone, K. A., Cui, H., \& Gerner, E. W. (2008). Combination chemoprevention of intestinal carcinogenesis in a murine model of familial adenomatous polyposis. Nutrition and Cancer, 60(SUPPL. 1), 30-35. https://doi.org/10.1080/01635580802401317

Jeter, J. M., Curiel-Lewandrowski, C., Stratton, S. P., Myrdal, P. B., Warneke, J. A., Einspahr, J. G., Bartels, H. G., Yozwiak, M., Bermudez, Y., Hu, C., Bartels, P., \& Alberts, D. S. (2016). Phase IIB randomized study of topical difluoromethylornithine and topical diclofenac on sun-damaged skin of the forearm. Cancer Prevention Research, 9(2), 128-134. https://doi.org/10.1158/1940-6207.CAPR-15-0232

Jia, Y., Ma, Z., Liu, X., Zhou, W., He, S., Xu, X., Ren, G., Xu, G., \& Tian, K. (2015). Metformin prevents DMH-induced colorectal cancer in diabetic rats by reversing the warburg effect. Cancer Medicine, 4(11), 1730-1741. https://doi.org/10.1002/cam4.521

Jin, C. Y., Park, C., Hwang, H. J., Kim, G. Y., Choi, B. T., Kim, W. J., \& Choi, Y. H. (2011). Naringenin up-regulates the expression of death receptor 5 and enhances TRAIL-induced apoptosis in human lung cancer A549 cells. Molecular Nutrition and Food Research, 55(2), 300-309. https://doi.org/10.1002/mnfr.201000024

Joanna, B., Jolanta, B., Agnieszka, G., Diana, H. Z., \& Krystyna, S. (2019). Vitamin D, linoleic acid, arachidonic acid and COX-2 in colorectal cancer patients in relation to disease stage, tumour localisation and disease progression. Arab Journal of Gastroenterology, 20(3), 121-126. https://doi.org/10.1016/j.ajg.2019.05.007 
Kamarudin, M. N. A., Sarker, M. M. R., Zhou, J. R., \& Parhar, I. (2019). Metformin in colorectal cancer: molecular mechanism, preclinical and clinical aspects. In Journal of Experimental and Clinical Cancer Research (Vol. 38, Issue 1, pp. 1-23). BioMed Central. https://doi.org/10.1186/s13046-019-1495-2

Kanematsu, S., Uehara, N., Miki, H., Yoshizawa, K., Kawanaka, A., Yuri, T., \& Tsubura, A. (n.d.). Autophagy Inhibition Enhances Sulforaphane-induced Apoptosis in Human Breast Cancer Cells.

Kasala, E. R., Bodduluru, L. N., Barua, C. C., Madhana, R. M., Dahiya, V., Budhani, M. K., Mallugari, R. R., Maramreddy, S. R., \& Gogoi, R. (2016). Chemopreventive effect of chrysin, a dietary flavone against benzo(a)pyrene induced lung carcinogenesis in Swiss albino mice. Pharmacological Reports, 68(2), 310-318. https://doi.org/10.1016/j.pharep.2015.08.014

Kasala, E. R., Bodduluru, L. N., Madana, R. M., Athira, K. V., Gogoi, R., \& Barua, C. C. (2015). Chemopreventive and therapeutic potential of chrysin in cancer: Mechanistic perspectives. Toxicology Letters, 233(2), 214-225. https://doi.org/10.1016/j.toxlet.2015.01.008

Katiyar, S. K., \& Elmets, C. A. (2001). Green tea polyphenolic antioxidants and skin photoprotection (Review). International Journal of Oncology, 18(6), 1307-1313. https://doi.org/10.3892/ijo.18.6.1307

Katiyar, Santosh K., Afaq, F., Azizuddin, K., \& Mukhtar, H. (2001). Inhibition of UVB-induced oxidative stress-mediated phosphorylation of mitogenactivated protein kinase signaling pathways in cultured human epidermal keratinocytes by green tea polyphenol ( - )-epigallocatechin-3-gallate. Toxicology and Applied Pharmacology, 176(2), 110-117. https://doi.org/10.1006/taap.2001.9276

Keith, R. L. (2009). Chemoprevention of lung cancer. Proceedings of the American Thoracic Society, 6(2), 187-193. https://doi.org/10.1513/pats.200807067LC

Keith, R. L., Blatchford, P. J., Kittelson, J., Minna, J. D., Kelly, K., Massion, P. P., Franklin, W. A., Mao, J., Wilson, D. O., Merrick, D. T., Hirsch, F. R., Kennedy, T. C., Bunn, P. A., Geraci, M. W., \& Miller, Y. E. (2011). Oral iloprost improves endobronchial dysplasia in former smokers. Cancer Prevention Research, 4(6), 793-802. https://doi.org/10.1158/1940-6207.CAPR-11-0057

Keith, R. L., Miller, Y. E., Hoshikawa, Y., Moore, M. D., Gesell, T. L., Gao, B., Malkinson, A. M., Golpon, H. A., Nemenoff, R. A., \& Geraci, M. W. (2002). Manipulation of Pulmonary Prostacyclin Synthase Expression Prevents Murine Lung Cancer. Cancer Research, 62(3).

Keith, R. L., Miller, Y. E., Hudish, T. M., Girod, C. E., Sotto-Santiago, S., Franklin, W. A., Nemenoff, R. A., March, T. H., Nana-Sinkam, S. P., \& Geraci, M. W. (2004). Pulmonary prostacyclin synthase overexpression chemoprevents tobacco smoke lung carcinogenesis in mice. Cancer Research, 64(16), 58975904. https://doi.org/10.1158/0008-5472.CAN-04-1070

Kelloff, G. J., Crowell, J. A., Steele, V. E., Lubet, R. A., Malone, W. A., Boone, C. W., Kopelovich, L., Hawk, E. T., Lieberman, R., Lawrence, J. A., Ali, I., Viner, J. L., \& Sigman, C. C. (2000). Progress in cancer chemoprevention: Development of diet-derived chemopreventive agents. Journal of Nutrition, 130(2 SUPPL.). https://doi.org/10.1093/jn/130.2.467s

Khare, S., Cerda, S., Wali, R. K., von Lintig, F. C., Tretiakova, M., Joseph, L., Stoiber, D., Cohen, G., Nimmagadda, K., Hart, J., Sitrin, M. D., Boss, G. R., \& Bissonnette, M. (2003). Ursodeoxycholic Acid Inhibits Ras Mutations, Wild-type Ras Activation, and Cyclooxygenase-2 Expression in Colon Cancer. Cancer Research, 63(13)

Kim, E. K., Cho, J. H., Kim, E. J., \& Kim, Y. J. (2017). Ursodeoxycholic acid inhibits the proliferation of colon cancer cells by regulating oxidative stress and cancer stem-like cell growth. PLOS ONE, 12(7), e0181183. https://doi.org/10.1371/journal.pone.0181183

Kim, S. J., Zhang, C. X. W., Demsky, R., Armel, S., Kim, Y. I., Narod, S. A., \& Kotsopoulos, J. (2019). Folic acid supplement use and breast cancer risk in BRCA1 and BRCA2 mutation carriers: a case-control study. Breast Cancer Research and Treatment, 174(3), 741-748. https://doi.org/10.1007/s10549-01805118-3

Kingsnorth, A. N., King, W. W. K., Diekema, K. A., McCann, P. P., Ross, J. S., \& Malt, R. A. (1983). Inhibition of Ornithine Decarboxylase with 2Difluoromethylornithine: Reduced Incidence of Dimethylhydrazine-induced Colon Tumors in Mice. Cancer Research, 43(6).

Koh, W. L., Oon, H. H., \& Tan, W. P. (2019). Acitretin-Altered Squamous Cell Carcinoma: A Pitfall in Diagnosis. Dermatologic Surgery, 45(2), 311-313. https://doi.org/10.1097/DSS.0000000000001558

Kozar, K., Kaminski, R., Legat, M., Kopec, M., Nowis, D., Skierski, J. S., Koronkiewicz, M., Jakóbisiak, M., \& Golab, J. (2004). Cerivastatin demonstrates enhanced antitumor activity against human breast cancer cell lines when used in combination with doxorubicin or cisplatin. International Journal of Oncology, 24(5), 1149-1157. https://doi.org/10.3892/ijo.24.5.1149

Kuršvietienė, L., Stanevičienė, I., Mongirdienė, A., \& Bernatonienė, J. (2016). Multiplicity of effects and health benefits of resveratrol. In Medicina (Lithuania) (Vol. 52, Issue 3, pp. 148-155). Elsevier B.V. https://doi.org/10.1016/j.medici.2016.03.003

Lee, D. A., \& Miller, S. J. (2009). Nonmelanoma Skin Cancer. Facial Plastic Surgery Clinics of North America, 17(3), 309-324. https://doi.org/10.1016/j.fsc.2009.04.004

Lee, J. Y., Sim, T.-B., Lee, J., \& Na, H.-K. (2017). Chemopreventive and Chemotherapeutic Effects of Fish Oil derived Omega-3 Polyunsaturated Fatty Acids on Colon Carcinogenesis. Clinical Nutrition Research, 6(3), 147. https://doi.org/10.7762/cnr.2017.6.3.147

Lenihan-Geels, G., Bishop, K., \& Ferguson, L. (2016). Cancer Risk and Eicosanoid Production: Interaction between the Protective Effect of Long Chain Omega-3 Polyunsaturated Fatty Acid Intake and Genotype. Journal of Clinical Medicine, 5(2), 25. https://doi.org/10.3390/jcm5020025

Leone, A., Diorio, G., Sexton, W., Schell, M., Alexandrow, M., Fahey, J. W., \& Kumar, N. B. (2017). Sulforaphane for the chemoprevention of bladder cancer: Molecular mechanism targeted approach. In Oncotarget (Vol. 8, Issue 21, pp. 35412-35424). Impact Journals LLC. https://doi.org/10.18632/oncotarget.16015

Li, F., Dou, J., Wei, L., Li, S., \& Liu, J. (2016). The selective estrogen receptor modulators in breast cancer prevention. Cancer Chemotherapy and 
Pharmacology, 77(5), 895-903. https://doi.org/10.1007/s00280-016-2959-0

Li, S., Shen, Y., Wang, M., Yang, J., Lv, M., Li, P., Chen, Z., \& Yang, J. (2017). Loss of PTEN expression in breast cancer: Association with clinicopathological characteristics and prognosis. Oncotarget, 8(19), 32043-32054. https://doi.org/10.18632/oncotarget.16761

Li, Y., He, X., Ding, Y., Chen, H., \& Sun, L. (2019). Statin uses and mortality in colorectal cancer patients: An updated systematic review and meta-analysis. Cancer Medicine, 8(6), 3305-3313. https://doi.org/10.1002/cam4.2151

Linares, M. A., Zakaria, A., \& Nizran, P. (2015). Skin Cancer. Primary Care - Clinics in Office Practice, 42(4), 645-659. https://doi.org/10.1016/j.pop.2015.07.006

Liong, M. T. (2008). Roles of probiotics and prebiotics in colon cancer prevention: Postulated mechanisms and in-vivo evidence. International Journal of Molecular Sciences, 9(5), 854-863. https://doi.org/10.3390/ijms9050854

Locker, G. Y., Mansel, R., Cella, D., Dobrez, D., Sorensen, S., \& Gandhi, S. K. (2007). Cost-effectiveness analysis of anastrozole versus tamoxifen as primary adjuvant therapy for postmenopausal women with early breast cancer: A US healthcare system perspective. The 5-year completed treatment analysis of the ATAC ("Arimidex", Tamoxifen Alone. Breast Cancer Research and Treatment, 106(2), 229-238. https://doi.org/10.1007/s10549-006-9483-6

Lü, J., Zhang, J., Jiang, C., Deng, Y., Özten, N., \& Bosland, M. C. (2016). Cancer chemoprevention research with selenium in the post-SELECT era: Promises and challenges. Nutr Cancer, 68(1), 1-17. https://doi.org/10.1080/01635581.2016.1105267

Lu, Y. P., Lou, Y. R., Liao, J., Xie, J. G., Peng, Q. Y., Yang, C. S., \& Conney, A. H. (2005). Administration of green tea or caffeine enhances the disappearance of UVB-induced patches of mutant $\mathrm{p} 53$ positive epidermal cells in SKH-1 mice. Carcinogenesis, $26(8), 21465-1472$. https://doi.org/10.1093/carcin/bgi086

Lu, Y. P., Lou, Y. R., Xie, J. G., Peng, Q. Y., Liao, J., Yang, C. S., Huang, M. T., \& Conney, A. H. (2002). Topical applications of caffeine or (-)epigallocatechin gallate (EGCG) inhibit carcinogenesis and selectively increase apoptosis in UVB-induced skin tumors in mice. Proceedings of the National Academy of Sciences of the United States of America, 99(19), 12455-12460. https://doi.org/10.1073/pnas.182429899

Lux, M. P., Wöckel, A., Benedict, A., Buchholz, S., Kreif, N., Harbeck, N., Kreienberg, R., Kaufmann, M., Beckmann, M. W., Jonat, W., Hadji, P., Distler, W., Raab, G., Tesch, H., Weyers, G., Possinger, K., \& Schneeweiss, A. (2010). Cost-effectiveness analysis of anastrozole versus tamoxifen in adjuvant therapy for early-stage breast cancer - A health-economic analysis based on the 100-month analysis of the atac trial and the German health system. Onkologie, 33(4), 155-166. https://doi.org/10.1159/000286233

Macedo, T. M. B., Schmourlo, G., \& Viana, K. D. A. L. (2012). Fibra alimentar como mecanismo preventivo de doenças crônicas e distúrbios metabólicos. Revista UNI, 2(2), 67-77.

Mahmoud, A. M., Yang, W., \& Bosland, M. C. (2014). Soy isoflavones and prostate cancer: A review of molecular mechanisms. In Journal of Steroid Biochemistry and Molecular Biology (Vol. 140, pp. 116-132). NIH Public Access. https://doi.org/10.1016/j.jsbmb.2013.12.010

Maia, P. L., Fiorio, B. de C., \& da Silva, F. R. (2018). A influência da microbiota intestinal na prevenção do câncer de cólon. Arquivos Catarinenses de Medicina, 47(1), 182-197. http://www.acm.org.br/acm/seer/index.php/arquivos/article/view/281

Mantena, S. K., Roy, A. M., \& Katiyar, S. K. (2018). Retraction to: Epigallocatechin-3-Gallate Inhibits Photocarcinogenesis Through Inhibition of Angiogenic Factors and Activation of CD8+ T Cells in Tumors (Photochemistry and Photobiology, (2005), 81, 5, (1174), 10.1562/2005-04-11-RA-487). Photochemistry and Photobiology, 94(3), 618. https://doi.org/10.1111/php.12904

Margolese, R. G., Cecchini, R. S., Julian, T. B., Ganz, P. A., Costantino, J. P., Vallow, L. A., Albain, K. S., Whitworth, P. W., Cianfrocca, M. E., Brufsky, A. M., Gross, H. M., Soori, G. S., Hopkins, J. O., Fehrenbacher, L., Sturtz, K., Wozniak, T. F., Seay, T. E., Mamounas, E. P., \& Wolmark, N. (2016). Anastrozole versus tamoxifen in postmenopausal women with ductal carcinoma in situ undergoing lumpectomy plus radiotherapy (NSABP B-35): A randomised, doubleblind, phase 3 clinical trial. The Lancet, 387(10021), 849-856. https://doi.org/10.1016/S0140-6736(15)01168-X

Marques, D., Lima, M., Santos, S. J., \& Marques, A. G. (2019). Perfil epidemiológico dos óbitos ocorridos no Brasil em decorrência de câncer colorretal no período de 2012-2016. Academus Revista Científica Da Saúde, 04(03), 7-16. https://doi.org/10.24118/reva1806.9495.4.3.2019.563

Marques, L. S. G., \& Neves, P. de B. O. (2013). A eficácia da ingestão de flavonóides na prevenção de neoplasias: uma revisão. Revista EVS - Revista de Ciências Ambientais e Saúde, 4(4), 585-594. https://doi.org/10.18224/EST.V40I4.3060

Martirosyan, A., Clendening, J. W., Goard, C. A., \& Penn, L. Z. (2010). Lovastatin induces apoptosis of ovarian cancer cells and synergizes with doxorubicin: Potential therapeutic relevance. BMC Cancer, 10. https://doi.org/10.1186/1471-2407-10-103

Melnik, B. C. (2017). Apoptosis may explain the pharmacological mode of action and adverse effects of isotretinoin, including teratogenicity. Acta DermatoVenereologica, 97(2), 173-181. https://doi.org/10.2340/00015555-2535

Mesolella, M., Iengo, M., Testa, D., Ricciardiello, F., \& Iorio, B. (2017). Chemoprevention using folic acid for dysplastic lesions of the larynx. Molecular and Clinical Oncology, 7(5), 843-846. https://doi.org/10.3892/mco.2017.1424

Meyskens, F. L., Gerner, E. W., Emerson, S., Pelot, D., Durbin, T., Doyle, K., \& Lagerberg, W. (1998). Effect of $\alpha$-difluoromethylornithine on rectal mucosal levels of polyamines in a randomized, double-blinded trial for colon cancer prevention. Journal of the National Cancer Institute, 90(16), 1212-1218. https://doi.org/10.1093/jnci/90.16.1212

Meyskens, F. L., Kingsley, E. M., Glattke, T., Loescher, L., \& Booth, A. (1986). A phase II study of $\alpha$-difluoromethylornithine (DFMO) for the treatment of metastatic melanoma. Investigational New Drugs, 4(3), 257-262. https://doi.org/10.1007/BF00179593

Meyskens, F. L., McLaren, C. E., Pelot, D., Fujikawa-Brooks, S., Carpenter, P. M., Hawk, E., Kelloff, G., Lawson, M. J., Kidao, J., McCracken, J., Albers, C. G., Ahnen, D. J., Turgeon, D. K., Goldschmid, S., Lance, P., Hagedorn, C. H., Gillen, D. L., \& Gerner, E. W. (2008). Difluoromethylornithine plus sulindac for the prevention of sporadic colorectal adenomas: A randomized placebo-controlled, double-blind trial. Cancer Prevention Research, 1(1), 32-38. 
https://doi.org/10.1158/1940-6207.CAPR-08-0042

Mika, A., Kobiela, J., Pakiet, A., Czumaj, A., Sokołowska, E., Makarewicz, W., Chmielewski, M., Stepnowski, P., Marino-Gammazza, A., \& Sledzinski, T. (2020). Preferential uptake of polyunsaturated fatty acids by colorectal cancer cells. Scientific Reports, 10(1). https://doi.org/10.1038/s41598-020-58895-7

Millea, P. J. (2009). N-Acetylcysteine: Multiple Clinical Applications. In American Family Physician (Vol. 80, Issue 3). www.aafp.org/afp.

Mocellin, S., Briarava, M., \& Pilati, P. (2017). Vitamin B6 and cancer risk: A field synopsis and meta-analysis. In Journal of the National Cancer Institute (Vol. 109, Issue 3). Oxford University Press. https://doi.org/10.1093/jnci/djw230

Mohammed, A., Yarla, N. S., Madka, V., \& Rao, C. V. (2018). Clinically relevant anti-inflammatory agents for chemoprevention of colorectal cancer: New perspectives. International Journal of Molecular Sciences, 19(8). https://doi.org/10.3390/ijms19082332

Mokbel, K., Wazir, U., \& Mokbel, K. (2019). Chemoprevention of prostate cancer by natural agents: Evidence from molecular and epidemiological studies. In Anticancer Research (Vol. 39, Issue 10, pp. 5231-5259). International Institute of Anticancer Research. https://doi.org/10.21873/anticanres.13720

Mondul, A. M., Weinstein, S. J., Layne, T. M., \& Albanes, D. (2017). Vitamin D and cancer risk and mortality: State of the science, gaps, and challenges. Epidemiologic Reviews, 39(1), 28-48. https://doi.org/10.1093/epirev/mxx005

Monteillier, A., Voisin, A., Furrer, P., Allémann, E., \& Cuendet, M. (2018). Intranasal administration of resveratrol successfully prevents lung cancer in A/J mice OPEN. Scientific REPORTs |, 8, 14257. https://doi.org/10.1038/s41598-018-32423-0

Moore, G. Y., \& Pidgeon, G. P. (2017). Cross-talk between cancer cells and the tumour microenvironment: The role of the 5-lipoxygenase pathway. International Journal of Molecular Sciences, 18(2). https://doi.org/10.3390/ijms18020236

Moura, N. A. de. (2015). Efeitos da ingestão de simbiótico e indol-3-carbinol sobre o processo de carcinogênese química de cólon em ratos Wistar alimentados com dieta contendo heme [Universidade Estadual Paulista (UNESP)]. https://repositorio.unesp.br/handle/11449/138850

Muller, A. G., Sarker, S. D., Saleem, I. Y., \& Hutcheon, G. A. (2019). Delivery of natural phenolic compounds for the potential treatment of lung cancer. DARU, Journal of Pharmaceutical Sciences, 27(1), 433-449. https://doi.org/10.1007/s40199-019-00267-2

Murakami, R., Chen, C., Lyu, S. Y., Lin, C. E., Tzeng, P. C., Wang, T. F., Chang, J. C., Shieh, Y. H., Chen, I. F., Huang, S. K., \& Lin, H. W. (2016). Lovastatin lowers the risk of breast cancer: a population-based study using logistic regression with a random effects model. SpringerPlus, 5(1). https://doi.org/10.1186/s40064-016-3606-2

Musial, C., Kuban-Jankowska, A., \& Gorska-Ponikowska, M. (2020). Beneficial properties of green tea catechins. International Journal of Molecular Sciences, 21(5). https://doi.org/10.3390/ijms21051744

Nangia-Makker, P., Yu, Y., Vasudevan, A., Farhana, L., Rajendra, S. G., Levi, E., \& Majumdar, A. P. N. (2014). Metformin: A potential therapeutic agent for recurrent colon cancer. PLoS ONE, 9(1), 84369. https://doi.org/10.1371/journal.pone.0084369

National Lung Screening Trial Research Team. (2019). Lung Cancer Incidence and Mortality with Extended Follow-up in the National Lung Screening Trial. Journal of Thoracic Oncology, 14(10), 1732-1742. https://doi.org/10.1016/j.jtho.2019.05.044

Nelson, C., Rigel, D., Smith, S., Swanson, N., \& Wolf, J. (2004). Phase IV, open-label assessment of the treatment of actinic keratosis with $3.0 \%$ diclofenac sodium topical gel (Solaraze). Journal of Drugs in Dermatology : JDD, 3(4), 401-407.

Nepomuceno, J. C. (2005). Dieta e câncer: vitaminas antioxidantes. Biosci. J, 21(1), 141-146.

New, M., \& Keith, R. (2018). Early Detection and Chemoprevention of Lung Cancer. F1000Research, 7. https://doi.org/10.12688/f1000research.12433.1

Ng, K., Meyerhardt, J. A., Wu, K., Feskanich, D., Hollis, B. W., Giovannucci, E. L., \& Fuchs, C. S. (2008). Circulating 25-hydroxyvitamin D levels and survival in patients with colorectal cancer. Journal of Clinical Oncology, 26(18), 2984-2991. https://doi.org/10.1200/JCO.2007.15.1027

Noah-Vanhoucke, J., Green, L. E., Dinh, T. A., Alperin, P., \& Smith, R. A. (2011). Cost-effectiveness of chemoprevention of breast cancer using tamoxifen in a postmenopausal US population. Cancer, 117(15), 3322-3331. https://doi.org/10.1002/cncr.25926

Nogueira, C. W., \& Rocha, J. B. T. (2010). Diphenyl diselenide a janus-faced molecule. In Journal of the Brazilian Chemical Society (Vol. 21, Issue 11, pp. 2055-2071). Sociedade Brasileira de Quimica. https://doi.org/10.1590/S0103-50532010001100006

Pardi, D. S., Loftus, E. V., Kremers, W. K., Keach, J., \& Lindor, K. D. (2003). Ursodeoxycholic acid as a chemopreventive agent in patients with ulcerative colitis and primary sclerosing cholangitis. Gastroenterology, 124(4), 889-893. https://doi.org/10.1053/gast.2003.50156

Patel, V. B., Misra, S., Patel, B. B., \& Majumdar, A. P. N. (2010). Colorectal cancer: Chemopreventive role of curcumin and resveratrol. In Nutrition and Cancer (Vol. 62, Issue 7, pp. 958-967). Nutr Cancer. https://doi.org/10.1080/01635581.2010.510259

Peck, G. L., DiGiovanna, J. J., Sarnoff, D. S., Gross, E. G., Butkus, D., Olsen, T. G., \& Yoder, F. W. (1988). Treatment and prevention of basal cell carcinoma with oral isotretinoin. Journal of the American Academy of Dermatology, 19(1), 176-185. https://doi.org/10.1016/S0190-9622(88)70162-0

Peck, G. L., Gross, E. G., Butkus, D., \& DiGiovanna, J. J. (1982). Chemoprevention of basal cell carcinoma with isotretinoin. Journal of the American Academy of Dermatology, 6(4), 815-823. https://doi.org/10.1016/S0190-9622(82)70071-4

Pei, Y., Liu, H., Yang, Y., Yang, Y., Jiao, Y., Tay, F. R., \& Chen, J. (2018). Biological activities and potential oral applications of N-acetylcysteine: Progress and prospects. In Oxidative Medicine and Cellular Longevity (Vol. 2018). Hindawi Limited. https://doi.org/10.1155/2018/2835787

Pennock, N. D., Martinson, H. A., Guo, Q., Betts, C. B., Jindal, S., Tsujikawa, T., Coussens, L. M., Borges, V. F., \& Schedin, P. (2018). Ibuprofen supports macrophage differentiation, $\mathrm{T}$ cell recruitment, and tumor suppression in a model of postpartum breast cancer 11 Medical and Health Sciences 1112 Oncology 
and Carcinogenesis 11 Medical and Health Sciences 1107 Immunology. Journal for ImmunoTherapy of Cancer, 6(1). https://doi.org/10.1186/s40425-0180406-y

Penny, L. K., \& Wallace, H. M. (2015). The challenges for cancer chemoprevention. Chemical Society Reviews, 44(24), 8836-8847. https://doi.org/10.1039/c5cs00705d

Pereira, A.S., Shitsuca, D.M, Parreira, F.J., \& Shitsuca, R. (2018). Metodologia da pesquisa científica. [free e-bool]. Santa Maria/RS. Ed. UAB/NTE/UFSM.

Pietrzak, S., Wójcik, J., Scott, R. J., Kashyap, A., Grodzki, T., Baszuk, P., Bielewicz, M., Marciniak, W., Wójcik, N., Dębniak, T., Masojć, B., Pieróg, J., Cybulski, C., Gronwald, J., Wojtyś, M., Kubisa, B., Sukiennicki, G., Deptuła, J., Waloszczyk, P., ... Lener, M. R. (2019). Influence of the selenium level on overall survival in lung cancer. Journal of Trace Elements in Medicine and Biology, 56, 46-51. https://doi.org/10.1016/j.jtemb.2019.07.010

Poulard, C., Corbo, L., \& Le Romancer, M. (2016). Protein arginine methylation/demethylation and cancer. In Oncotarget (Vol. 7, Issue 41, pp. 6753267550). Impact Journals LLC. https://doi.org/10.18632/oncotarget.11376

Prado, R., Francis, S. O., Mason, M. N., Wing, G., Gamble, R. G., \& Dellavalle, R. (2011). Nonmelanoma skin cancer chemoprevention. Dermatologic Surgery, 37(11), 1566-1578. https://doi.org/10.1111/j.1524-4725.2011.02108.x

Rao, M., \& Rao, M. N. A. (1998). Protective effects of selenomethionine against cisplatin-induced renal toxicity in mice and rats. Journal of Pharmacy and Pharmacology, 50(6), 687-691. https://doi.org/10.1111/j.2042-7158.1998.tb06906.x

Rauf, A., Imran, M., Khan, I. A., Ur-Rehman, M., Gilani, S. A., Mehmood, Z., \& Mubarak, M. S. (2018). Anticancer potential of quercetin: A comprehensive review. Phytotherapy Research, 32(11), 2109-2130. https://doi.org/10.1002/ptr.6155

Rees, J. R., Stukel, T. A., Perry, A. E., Zens, M. S., Spencer, S. K., \& Karagas, M. R. (2007). Tea consumption and basal cell and squamous cell skin cancer: Results of a case-control study. Journal of the American Academy of Dermatology, 56(5), 781-785. https://doi.org/10.1016/j.jaad.2006.11.038

Reinau, D., Surber, C., Jick, S. S., \& Meier, C. R. (2015). Nonsteroidal anti-inflammatory drugs and the risk of nonmelanoma skin cancer. International Journal of Cancer, 137(1), 144-153. https://doi.org/10.1002/ijc.29357

Rivers, J. K., Arlette, J., Shear, N., Guenther, L., Carey, W., \& Poulin, Y. (2002). Topical treatment of actinic keratoses with 3.0\% diclofenac in 2.5\% hyaluronan gel. British Journal of Dermatology, 146(1), 94-100. https://doi.org/10.1046/j.1365-2133.2002.04561.x

Rojas, K., \& Stuckey, A. (2016). Breast Cancer Epidemiology and Risk Factors. Clinical Obstetrics and Gynecology, 59(4), 651-672. https://doi.org/10.1097/GRF.0000000000000239

Roncucci, L., \& Mariani, F. (2015). Prevention of colorectal cancer: How many tools do we have in our basket? European Journal of Internal Medicine, 26(10), 752-756. https://doi.org/10.1016/j.ejim.2015.08.019

Ruhstaller, T., Giobbie-Hurder, A., Colleoni, M., Jensen, M. B., Ejlertsen, B., De Azambuja, E., Neven, P., Láng, I., Jakobsen, E. H., Gladieff, L., Bonnefoi, H., Harvey, V. J., Spazzapan, S., Tondini, C., Del Mastro, L., Veyret, C., Simoncini, E., Gianni, L., Rochlitz, C., ... Regan, M. M. (2019). Adjuvant letrozole and tamoxifen alone or sequentially for postmenopausal women with hormone receptor-positive breast cancer: Long-term follow-up of the BiG 1-98 trial. Journal of Clinical Oncology, 37(2), 105-114. https://doi.org/10.1200/JCO.18.00440

Russo, M., Spagnuolo, C., Russo, G. L., Skalicka-Woźniak, K., Daglia, M., Sobarzo-Sánchez, E., Nabavi, S. F., \& Nabavi, S. M. (2018). Nrf2 targeting by sulforaphane: A potential therapy for cancer treatment. Critical Reviews in Food Science and Nutrition, 58(8), 1391-1405. https://doi.org/10.1080/10408398.2016.1259983

Salehi, B., Fokou, P. V. T., Sharifi-Rad, M., Zucca, P., Pezzani, R., Martins, N., \& Sharifi-Rad, J. (2019). The therapeutic potential of naringenin: A review of clinical trials. Pharmaceuticals, 12(1). https://doi.org/10.3390/ph12010011

Santarelli, R. L., Pierre, F., \& Corpet, D. E. (2008). Processed meat and colorectal cancer: A review of epidemiologic and experimental evidence. In Nutrition and Cancer (Vol. 60, Issue 2, pp. 131-144). Nutr Cancer. https://doi.org/10.1080/01635580701684872

Sehgal, P., Colombel, J. F., Aboubakr, A., \& Narula, N. (2018). Systematic review: safety of mesalazine in ulcerative colitis. Alimentary Pharmacology and Therapeutics, 47(12), 1597-1609. https://doi.org/10.1111/apt.14688

Serfaty, L., De Leusse, A., Rosmorduc, O., Desaint, B., Flejou, J. F., Chazouilleres, O., Poupon, R. E., \& Poupon, R. (2003). Ursodeoxycholic acid therapy and the risk of colorectal adenoma in patients with primary biliary cirrhosis: An observational study. Hepatology, 38(1), 203-209. https://doi.org/10.1053/jhep.2003.50311

Serrano, D., Lazzeroni, M., \& Bonanni, B. (2015). Cancer chemoprevention: Much has been done, but there is still much to do. State of the art and possible new approaches. In Molecular Oncology (Vol. 9, Issue 5, pp. 1008-1017). Elsevier B.V. https://doi.org/10.1016/j.molonc.2014.12.006

Shaito, A., Posadino, A. M., Younes, N., Hasan, H., Halabi, S., Alhababi, D., Al-Mohannadi, A., Abdel-Rahman, W. M., Eid, A. H., Nasrallah, G. K., \& Pintus, G. (2020). Potential adverse effects of resveratrol: A literature review. In International Journal of Molecular Sciences (Vol. 21, Issue 6, p. 2084). MDPI AG. https://doi.org/10.3390/ijms21062084

Sharaf, L. K., Sharma, M., Chandel, D., \& Shukla, G. (2018). Prophylactic intervention of probiotics (L.acidophilus, L.rhamnosus GG) and celecoxib modulate Bax-mediated apoptosis in 1,2-dimethylhydrazine-induced experimental colon carcinogenesis. BMC Cancer, 18(1), 1-13. https://doi.org/10.1186/s12885-018-4999-9

Sharma, P., Montes de Oca, M. K., Alkeswani, A. R., McClees, S. F., Das, T., Elmets, C. A., \& Afaq, F. (2018). Tea polyphenols for the prevention of UVBinduced skin cancer. Photodermatology Photoimmunology and Photomedicine, 34(1), 50-59. https://doi.org/10.1111/phpp.12356

Shirakami, Y., \& Shimizu, M. (2018). Possible mechanisms of green tea and its constituents against cancer. Molecules, 23(9). https://doi.org/10.3390/molecules23092284 
Shree, G. S., Prasad, K. Y., Arpitha, H. S., Deepika, U. R., Kumar, K. N., Mondal, P., \& Ganesan, P. (2017). $\beta$-carotene at physiologically attainable concentration induces apoptosis and down-regulates cell survival and antioxidant markers in human breast cancer (MCF-7) cells. Molecular and Cellular Biochemistry, 436(1-2). https://doi.org/10.1007/s11010-017-3071-4

Siegel, R. L., Miller, K. D., \& Jemal, A. (2020). Cancer statistics, 2020. CA: A Cancer Journal for Clinicians, 70(1), 7-30. https://doi.org/10.3322/caac.21590 Silva, C. R. de M., \& Naves, M. M. V. (2001). Suplementaçäo de vitaminas na prevençäo de câncer. Rev. Nutr, 135-143. http://www.scielo.br/scielo.php?script=sci_arttext\&pid=S1415-52732001000200007\&lng=pt\&nrm=iso\&tlng=pt

Singh, B. N., Prateeksha, P., Rawat, A. K. S., Bhagat, R. M., \& Singh, B. R. (2017). Black tea: Phytochemicals, cancer chemoprevention, and clinical studies. Critical Reviews in Food Science and Nutrition, 57(7), 1394-1410. https://doi.org/10.1080/10408398.2014.994700

Smith, C. L., Santen, R. J., Komm, B., \& Mirkin, S. (2014). Breast-related effects of selective estrogen receptor modulators and tissue-selective estrogen complexes. Breast Cancer Research, 16(3), 1-15. https://doi.org/10.1186/bcr3677

Soltani-Arabshahi, R., \& Tristani-Firouzi, P. (2013). Chemoprevention of nonmelanoma skin cancer. Facial Plastic Surgery, 29(5), 373-383. https://doi.org/10.1055/s-0033-1353377

Soundararajan, P., \& Kim, J. S. (2018). Anti-carcinogenic glucosinolates in cruciferous vegetables and their antagonistic effects on prevention of cancers. In Molecules (Vol. 23, Issue 11). MDPI AG. https://doi.org/10.3390/molecules23112983

Spallholz, J. E. (2019). Selenomethionine and methioninase: Selenium free radical anticancer activity. In Methods in Molecular Biology (Vol. 1866, pp. 199210). Humana Press Inc. https://doi.org/10.1007/978-1-4939-8796-2_15

Stancu, C., \& Sima, A. (2001). Statins: Mechanism of action and effects. Journal of Cellular and Molecular Medicine, 5(4), 378-387. https://doi.org/10.1111/j.1582-4934.2001.tb00172.x

Stefanska, B., Salamé, P., Bednarek, A., \& Fabianowska-Majewska, K. (2012). Comparative effects of retinoic acid, vitamin D and resveratrol alone and in combination with adenosine analogues on methylation and expression of phosphatase and tensin homologue tumour suppressor gene in breast cancer cells. British Journal of Nutrition, 107(6), 781-790. https://doi.org/10.1017/S0007114511003631

Stolfi, C., Pallone, F., \& Monteleone, G. (2012). Colorectal cancer chemoprevention by mesalazine and its derivatives. In Journal of Biomedicine and Biotechnology (Vol. 2012). J Biomed Biotechnol. https://doi.org/10.1155/2012/980458

Ströhle, A., Wolters, M., \& Hahn, A. (2005). Folic acid and colorectal cancer prevention: molecular mechanisms and epidemiological evidence (Review). In International journal of oncology (Vol. 26, Issue 6, pp. 1449-1464). Spandidos Publications. https://doi.org/10.3892/ijo.26.6.1449

Sun, Y. S., Zhao, Z., Yang, Z. N., Xu, F., Lu, H. J., Zhu, Z. Y., Shi, W., Jiang, J., Yao, P. P., \& Zhu, H. P. (2017). Risk factors and preventions of breast cancer. In International Journal of Biological Sciences (Vol. 13, Issue 11, pp. 1387-1397). Ivyspring International Publisher. https://doi.org/10.7150/ijbs.21635

Surh, Y. J. (2003). Cancer chemoprevention with dietary phytochemicals. In Nature Reviews Cancer (Vol. 3, Issue 10, pp. 768-780). European Association for Cardio-Thoracic Surgery. https://doi.org/10.1038/nrc1189

Sutherland, R. L., Ormsbee, J., Pader, J., Forbes, N., Town, S., Hilsden, R. J., \& Brenner, D. R. (2020). Vitamin D supplementation reduces the occurrence of colorectal polyps in high-latitude locations. Preventive Medicine, 135. https://doi.org/10.1016/j.ypmed.2020.106072

Szende, B., Tyihák, E., \& Trézl, L. (2001). Role of arginine and its methylated derivatives in cancer biology and treatment. Cancer Cell International, 1(1), 1. https://doi.org/10.1186/1475-2867-1-3

Tagliabue, E., Raimondi, S., \& Gandini, S. (2015). Vitamin D, Cancer Risk, and Mortality. In Advances in Food and Nutrition Research (1st ed., Vol. 75). Elsevier Inc. https://doi.org/10.1016/bs.afnr.2015.06.003

Tan, H. W., Mo, H. Y., Lau, A. T. Y., \& Xu, Y. M. (2019). Selenium species: Current status and potentials in cancer prevention and therapy. International Journal of Molecular Sciences, 20(1). https://doi.org/10.3390/ijms20010075

Thiebaud, D., \& Secrest, R. J. (2001). Selective estrogen receptor modulators: Mechanism of action and clinical experience. Focus on raloxifene. Reproduction, Fertility and Development, 13(4), 331-336. https://doi.org/10.1071/RD00109

Thompson, P. A., Ashbeck, E. L., Roe, D. J., Fales, L., Buckmeier, J., Wang, F., Bhattacharyya, A., Hsu, C. H., Chow, S. H. H., Ahnen, D. J., Boland, C. R., Heigh, R. I., Fay, D. E., Hamilton, S. R., Jacobs, E. T., Martinez, E. M., Alberts, D. S., \& Lance, P. (2016). Celecoxib for the prevention of colorectal adenomas: Results of a suspended randomized controlled trial. Journal of the National Cancer Institute, 108(12). https://doi.org/10.1093/jnci/djw151

Tinsley, H. N., Grizzle, W. E., Abadi, A., Keeton, A., Zhu, B., Xi, Y., \& Piazza, G. A. (2013). New NSAID targets and derivatives for colorectal cancer chemoprevention. Recent Results in Cancer Research, 191, 105-120. https://doi.org/10.1007/978-3-642-30331-9_6

Tiptiri-Kourpeti, A., Spyridopoulou, K., Santarmaki, V., Aindelis, G., Tompoulidou, E., Lamprianidou, E. E., Saxami, G., Ypsilantis, P., Lampri, E. S., Simopoulos, C., Kotsianidis, I., Galanis, A., Kourkoutas, Y., Dimitrellou, D., \& Chlichlia, K. (2016). Lactobacillus casei exerts anti-proliferative effects accompanied by apoptotic cell death and up-regulation of TRAIL in colon carcinoma cells. PLoS ONE, 11(2), 1-20. https://doi.org/10.1371/journal.pone.0147960

Tsai, M. J., Wu, P. H., Sheu, C. C., Hsu, Y. L., Chang, W. A., Hung, J. Y., Yang, C. J., Yang, Y. H., Kuo, P. L., \& Huang, M. S. (2016). Cysteinyl Leukotriene Receptor Antagonists Decrease Cancer Risk in Asthma Patients. Scientific Reports, 6. https://doi.org/10.1038/srep23979

Tsioulias, G. J., Go, M. F., \& Rigas, B. (2015). NSAIDs and Colorectal Cancer Control: Promise and Challenges. Current Pharmacology Reports, 1(5), 295301. https://doi.org/10.1007/s40495-015-0042-x 
Tung, B. Y., Emond, M. J., Haggitt, R. C., Bronner, M. P., Kimmey, M. B., Kowdley, K. V., \& Brentnall, T. A. (2001). Ursodiol use is associated with lower prevalence of colonic neoplasia in patients with ulcerative colitis and primary sclerosing cholangitis. Annals of Internal Medicine, 134(2), 89-95. https://doi.org/10.7326/0003-4819-134-2-200101160-00008

Ueland, P. M., McCann, A., Midttun, Ø., \& Ulvik, A. (2017). Inflammation, vitamin B6 and related pathways. In Molecular Aspects of Medicine (Vol. 53, pp. 10-27). Elsevier Ltd. https://doi.org/10.1016/j.mam.2016.08.001

Vandenplas, Y., Huys, G., \& Daube, G. (2015). Probiotics: an update. J Pediatr (Rio J), 91(1), 6-21. https://doi.org/10.1016/j.jped.2014.08.005

Vanduchova, A., Anzenbacher, P., \& Anzenbacherova, E. (2019). Isothiocyanate from Broccoli, Sulforaphane, and Its Properties. Journal of Medicinal Food, 22(2), 121-126. https://doi.org/10.1089/jmf.2018.0024

Vaughan-Shaw, P. G., O'Sullivan, F., Farrington, S. M., Theodoratou, E., Campbell, H., Dunlop, M. G., \& Zgaga, L. (2017). The impact of Vitamin D pathway genetic variation and circulating 25-hydroxyVitamin D on cancer outcome: Systematic review and meta-Analysis. British Journal of Cancer, 116(8), 1095-1110. https://doi.org/10.1038/bjc.2017.44

Veettil, S. K., Nathisuwan, S., Ching, S. M., Jinatongthai, P., Lim, K. G., Kew, S. T., \& Chaiyakunapruk, N. (2019). Efficacy and safety of celecoxib on the incidence of recurrent colorectal adenomas: A systematic review and meta-analysis. In Cancer Management and Research (Vol. 11, pp. 561-571). Dove Medical Press Ltd. https://doi.org/10.2147/CMAR.S180261

Vella, V., Nicolosi, M. L., Giuliano, S., Bellomo, M., Belfiore, A., \& Malaguarnera, R. (2017). PPAR- $\gamma$ agonists as antineoplastic agents in cancers with dysregulated IGF axis. Frontiers in Endocrinology, 8(FEB), 1. https://doi.org/10.3389/fendo.2017.00031

Vogel, V. G. (2014). Role of Hormones in Cancer Prevention. American Society of Clinical Oncology Educational Book, 34, 34-40. https://doi.org/10.14694/edbook_am.2014.34.34

Volpato, M., \& Hull, M. A. (2018). Omega-3 polyunsaturated fatty acids as adjuvant therapy of colorectal cancer. Cancer and Metastasis Reviews, 37(2-3), 545-555. https://doi.org/10.1007/s10555-018-9744-y

Waters, E. A., McNeel, T. S., Stevens, W. M., \& Freedman, A. N. (2012). Use of tamoxifen and raloxifene for breast cancer chemoprevention in 2010. Breast Cancer Research and Treatment, 134(2), 875-880. https://doi.org/10.1007/s10549-012-2089-2

Way, T. Der, Lee, H. H., Kao, M. C., \& Lin, J. K. (2004). Black tea polyphenol theaflavins inhibit aromatase activity and attenuate tamoxifen resistance in HER2/neu-transfected human breast cancer cells through tyrosine kinase suppression. European Journal of Cancer, 40(14), 2165-2174. https://doi.org/10.1016/j.ejca.2004.06.018

Wright, T. I., Spencer, J. M., \& Flowers, F. P. (2006). Chemoprevention of nonmelanoma skin cancer. Journal of the American Academy of Dermatology, 54(6), 933-946. https://doi.org/10.1016/j.jaad.2005.08.062

Wu, L., Li, J., Liu, T., Li, S., Feng, J., Yu, Q., Zhang, J., Chen, J., Zhou, Y., Ji, J., Chen, K., Mao, Y., Wang, F., Dai, W., Fan, X., Wu, J., \& Guo, C. (2019). Quercetin shows anti-tumor effect in hepatocellular carcinoma LM3 cells by abrogating JAK2/STAT3 signaling pathway. Cancer Medicine, 8(10), 48064820. https://doi.org/10.1002/cam4.2388

Wu, W., Kang, S., \& Zhang, D. (2013). Association of vitamin B 6, vitamin B 12 and methionine with risk of breast cancer: A dose-response meta-analysis. British Journal of Cancer, 109(7), 1926-1944. https://doi.org/10.1038/bjc.2013.438

Yan, Y., Gong, Z., \& Xu, Z. (2019). Vitamin D supplementation and colorectal cancer prognosis. Medical Oncology, 36(8), 1. https://doi.org/10.1007/s12032019-1293-X

Yang, W., Liu, L., Masugi, Y., Qian, Z. R., Nishihara, R., Wu, K., Smith-warner, S. A., Nowak, J. A., Zhang, L., Bowden, M., Morikawa, T., Wang, M., Chan, A. T., Fuchs, C. S., Jeffrey, A., Ng, K., Giovannucci, E., \& Ogino, S. (2019). Calcium intake and risk of colorectal cancer according to expression status of calcium-sensing receptor (CASR). Gut, 67(8), 1475-1483. https://doi.org/10.1136/gutjnl-2017-314163.Calcium

Yang, Z., Su, Z., DeWitt, J. P., Xie, L., Chen, Y., Li, X., Han, L., Li, D., Xia, J., Zhang, Y., Yang, Y., Jin, C., Zhang, J., Li, S., Li, K., Zhang, Z., Qu, X., He, Z., Chen, Y., ... Yuan, Z. (2017). Fluvastatin Prevents Lung Adenocarcinoma Bone Metastasis by Triggering Autophagy. EBioMedicine, 19, 49-59. https://doi.org/10.1016/j.ebiom.2017.04.017

Yarosh, D., Bucana, C., Cox, P., Alas, L., Kibitel, J., \& Kripke, M. (1994). Localization of liposomes containing a DNA repair enzyme in murine skin. Journal of Investigative Dermatology, 103(4), 461-468. https://doi.org/10.1111/1523-1747.ep12395551

Yarosh, D., Klein, J., O'Connor, A., Hawk, J., Rafal, E., \& Wolf, P. (2001). Effect of topically applied T4 endonuclease V in liposomes on skin cancer in xeroderma pigmentosum: A randomised study. Lancet, 357(9260), 926-929. https://doi.org/10.1016/S0140-6736(00)04214-8

Yurko-Mauro, K., Van Elswyk, M., \& Teo, L. (2020). A scoping review of interactions between omega-3 long-chain polyunsaturated fatty acids and genetic variation in relation to cancer risk. Nutrients, 12(6). https://doi.org/10.3390/nu12061647

Zadorozhna, M., Tataranni, T., \& Mangieri, D. (2019). Piperine: role in prevention and progression of cancer. In Molecular Biology Reports (Vol. 46, Issue 5, pp. 5617-5629). Springer Netherlands. https://doi.org/10.1007/s11033-019-04927-z

Zeng, J., Wang, K., Ye, F., Lei, L., Zhou, Y., Chen, J., Zhao, G., \& Chang, H. (2019). Folate intake and the risk of breast cancer: an up-to-date meta-analysis of prospective studies. European Journal of Clinical Nutrition, 73(12), 1657-1660. https://doi.org/10.1038/s41430-019-0394-0

Zhang, Z., Atwell, L. L., Farris, P. E., Ho, E., \& Shannon, J. (2016). Associations between cruciferous vegetable intake and selected biomarkers among women scheduled for breast biopsies. Public Health Nutrition, 19(7), 1288-1295. https://doi.org/10.1017/S136898001500244X

Zheng, S. Y., Li, Y., Jiang, D., Zhao, J., \& Ge, J. F. (2012). Anticancer effect and apoptosis induction by quercetin in the human lung cancer cell line A-549. 
Research, Society and Development, v. 10, n. 8, e44610817448, 2021

(CC BY 4.0) | ISSN 2525-3409 | DOI: http://dx.doi.org/10.33448/rsd-v10i8.17448

Molecular Medicine Reports, 5(3), 822-826. https://doi.org/10.3892/mmr.2011.726

Zhou, Q., Pan, H., \& Li, J. (2019). Molecular Insights into Potential Contributions of Natural Polyphenols to Lung Cancer Treatment. Cancers, 11(10). https://doi.org/10.3390/cancers11101565

Zi, F., Zi, H., Li, Y., He, J., Shi, Q., \& Cai, Z. (2018). Metformin and cancer: An existing drug for cancer prevention and therapy (review). In Oncology Letters (Vol. 15, Issue 1, pp. 683-690). Spandidos Publications. https://doi.org/10.3892/ol.2017.7412 